\title{
Melatonergic agents influence the sleep-wake and circadian rhythms in healthy and psychiatric participants: a systematic review and meta-analysis of randomized controlled trials
}

\author{
Eunsoo Moon ${ }^{1,2}$, Timo Partonen (iD) ${ }^{3}$, Serge Beaulieu ${ }^{4,5}$ and Outi Linnaranta ${ }^{3,4,5}$ 圧 \\ (c) The Author(s) 2022
}

Exogenous melatonergic agents are widely used to treat insomnia and sleep disturbance. Several studies have shown that they might also modulate circadian rhythms. The purpose of this systematic review and meta-analysis was to summarize current knowledge about the effects of melatonin supplements and melatonin agonists on the sleep-wake cycle as well as on the circadian rhythm of melatonin in healthy participants and in patients with psychiatric disorders. The following electronic databases were searched: EMBASE, PubMed, Web of Science, CINAHL, and Cochrane Library. Of the 12,719 articles, we finally selected 30 studies including 1294 healthy participants and 8 studies including 687 patients with psychiatric disorders. Cochrane risk of bias tool was used to assess the risk of bias. Using meta-ANOVA, studies on healthy participants showed advancing effects of melatonergic supplements and agonists on sleep-wake cycle according to dosing time and dosage, despite the fact that the original individual melatonin rhythm was within a normal range (fixed effect model standardized mean difference [95\% Confidence Interval] $=-0.639$ [ -0.968 to -0.310$]$ ). In a limited number of randomized controlled trials with psychiatric patients, the findings seemed similar to those with healthy participants, despite the psychiatric disorders and treatment related factors affecting circadian rhythms. Given the unmet clinical need for evidence-based treatments to correct circadian rhythms in psychiatric disorders, efficacy of melatonergic agents seen in healthy participants, and similarity of findings among psychiatric patients, large scale, well-designed randomized controlled trials are needed to test efficacy on circadian parameters in psychiatric disorders.

Neuropsychopharmacology (2022) 47:1523-1536; https://doi.org/10.1038/s41386-022-01278-5

\section{INTRODUCTION}

Melatonin is an endogenous hormone that is one of the key regulators of circadian rhythms in humans. The endogenous melatonin rhythm exhibits a close association with the endogenous component of the sleep propensity rhythm. Administration of exogenous melatonin is able: (i) to enhance sleepiness when the homeostatic drive to sleep is insufficient; (ii) to inhibit the drive for wakefulness emanating from the circadian pacemaker; and (iii) to induce phase shifts in the circadian clock such that the circadian phase of increased sleep propensity occurs at a new, desired time [1]. Melatonin secreted from the central nervous system is also one of the modulators of the hypothalamic-pituitary-adrenal axis [2].

Efficacy of melatonergic agents as exogenous regulators of sleep timing and circadian rhythm has been established in different conditions in which there is a problem with sleep-wake cycles. Melatonin has been shown to advance the timing of sleep in delayed sleep-wake phase disorder (DSWPD) [3]. In addition, the effects of melatonin including sleep-promoting, phase-shifting, and entrainment effects were investigated on jet lag symptoms $[4,5]$, adaptation of shift workers [6, 7], and entrainment in non24-hour sleep-wake rhythm disorder (N24SWD) [8, 9]. Despite conflicting findings, several studies suggested potential effects on correcting and stabilizing circadian rhythm sleep-wake cycles [4, 5, 7-9]. Furthermore, there is some evidence for improving sleep quality in primary insomnia [10]. Data on melatonin receptor agonists are limited as compared to exogenous melatonin. Potential effects of tasimelteon have been reported in several studies with N24SWD, jet lag, and primary insomnia [11-15]. In addition, ramelteon has improved sleep quality and reduced latency to persistent sleep in primary insomnia, and corrected the timing of sleep in N24SWD [16, 17].

Patients with psychiatric disorders can show signs of disrupted circadian rhythms, particularly fragmentation and delayed phase, to the point where these characteristics have been considered as a core etiopathological factor [18]. Evidence for a disruption of circadian rhythm is robust especially in patients with bipolar disorders (BD) [19-22], including participants at high risk for BD, and is characterized by irregular rhythms, fragmentation and poor quality of sleep [20]. Patients with BD have also demonstrated a significantly lower peak of nocturnal melatonin levels (see a recent review [21]). Studies in patients with BD commonly report lower levels of overnight melatonin and delays in dim-light melatonin onset (DLMO) as compared to both patients with major depressive disorder (MDD) and healthy controls. However, one systematic

\footnotetext{
${ }^{1}$ Department of Psychiatry, Pusan National University School of Medicine, Yangsan, Republic of Korea. ${ }^{2}$ Department of Psychiatry and Biomedical Research Institute, Pusan National University Hospital, Busan, Republic of Korea. ${ }^{3}$ Department of Public Health and Welfare, Finnish Institute for Health and Welfare (THL), Helsinki, Finland. ${ }^{4}$ Department of

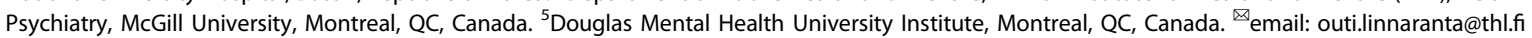


review and meta-analysis with both $\mathrm{BD}$ and schizophrenia reported that effect sizes for sleep onset latency (SOL), total sleep time (TST), and wake after sleep onset (WASO) were in schizophrenia even higher than those in BD [23]. Half of patients with schizophrenia showed severe circadian misalignment, such as delayed/advanced sleep-wake phases or non-24-h sleep-wake patterns [24]. Furthermore, abnormalities in circadian rhythms in MDD or seasonal affective disorder have been reported [25]. Patients with MDD have showed eveningness chronotype, decreased amplitudes, and phase delays or advances of the circadian rhythms such as core body temperature and melatonin [26-28], while sleep disturbances and phase delays or advances of the circadian rhythms were observed in patients with seasonal affective disorder [29, 30]. While sleeping and eating related behaviors have shared regulatory systems [31], findings in eating disorders support internal dysregulation. Patients with night-eating syndrome had delayed and blunted rhythms of food intake, leptin, insulin and melatonin, as compared with those rhythms in healthy controls [32]. Additionally, there were significant differences in parameters measured with actigraphy, such as midline estimating statistic of rhythm and amplitude of rest-activity cycles between patients with binge eating disorder and healthy controls [33]. The late sleep phase was robustly associated with irregular eating pattern in a mixed sample of patients with eating disorders, also reflecting dysregulated sleep-wake cycles [34]. Patients with attention deficit hyperactivity disorder (ADHD) have shown increased nocturnal activity as well as daytime activity [35]. Especially, the absence of post-lunch dip was observed [36]. These findings might suggest that the circadian component was enhanced, while the homeostatic component was weakened [36]. Furthermore, in ADHD patients, DSWPD was frequently reported [37]. Finally, delayed and fragmented sleep was also detected in patients with borderline personality disorder [38]. Interestingly, abnormalities in the circadian rhythms appear very similar transdiagnostically across psychiatric disorders, hence raising issues of specificity and the possibility that the observed findings on circadian rhythms might be an epiphenomenon of the disorganization caused by any psychiatric disorder.

Several methods have been used in trials in order to capture the features of circadian rhythms. To this end, the three-oscillator model provides a framework for explaining some of these features, with the assessment of core body temperature, wake onset, and sleep onset [39]. The most common method in studies on sleep for the assessment of sleep stages from sleep onset to sleep offset has been polysomnography (PSG) [40-42]. Even though PSG is the current gold standard measurement for sleep, problems in longitudinal assessment have hindered its use for research on circadian rhythms [43]. For a PSG measurement, the need for several sensors, whether in a laboratory or ambulatory setting, limits its use in longitudinal studies and in patients with fragmented sleep [44]. Results of consecutive recordings by PSG could be affected by the first-night effect and night-to-night variability [45]. Furthermore, high costs limit large-scale research. Given these problems, PSG is not practical to measure sleep-wake cycles longitudinally [41]. Another method is using accelerometers and actigraphy to describe rest-activity cycles [21]. Yet not recording the sleep-wake cycles nor circadian rhythms directly, recent methodological developments have provided novel actigraphic parameters to better capture disrupted rhythms, including fragmentation index [46], midpoint of sleep, and sleep consolidation as well as their variability [47]. Meanwhile, one of accurate descriptors of the circadian rhythms is DLMO [48]. Utility of the gold standard using melatonin assays from blood, urine or saliva samples is limited for larger scale trials, since it necessitates repeated measurements and is sensitive to light exposure [21]. Overall, these proper circadian parameters have rarely been the focus of trials with melatonin. While an accumulating number of meta-analyses describe the efficacy of melatoninergic agents in specific target populations $[16,49-51]$, unfortunately, most of them focus on outcome measures other than circadian rhythm parameters.
In this systematic review, we wanted to summarize the current knowledge on randomized controlled trials (RCTs) with exogenous melatonin or a melatonin agonist to guide treatment of disrupted circadian and sleep-wake rhythms. The first aim was to synthesize accumulating evidence that melatoninergic agents in healthy participants can have a phase advancing effect on circadian rhythms and consolidate sleep. The second aim was to integrate the knowledge about the effects of melatonergic agents on restactivity rhythms in psychiatric patients. The impact of exogenous melatonin in the psychiatric population could differ from that present in healthy participants due to factors which are related to the psychiatric disorder per se or other disorder-associated characteristics, most importantly, polypharmacy, behavioral factors, differences in external timers such as (lack of) work schedules, and obesity. While patients with distinct psychiatric disorders have commonly presented with delayed and disrupted rhythm sleep-wake disorders, melatonergic agents could be potentially optimal in treatment of these sleep problems. Thus, integrating knowledge about differences in the impact on circadian and sleep-wake rhythms between healthy participants and psychiatric patients is important to guide treatment of psychiatric patients but has not previously been done.

\section{METHODS}

We conducted a systematic review and, where possible, meta-analysis to investigate the effect of melatonergic agents in healthy participants and psychiatric patients. A systematic review and meta-analysis was undertaken according to the Preferred Reporting Items for Systematic reviews and Meta-Analyses guideline (Supplementary Table 1). The study protocol was registered at Open Science Framework (https://osf.io/hytxv/).

\section{Key question}

The purpose of this review was to investigate the effects of melatonergic agents (e.g., exogenous melatonin, prolonged released melatonin, melatonin receptor agonists) on the parameters of melatonin rhythm and sleep-wake cycle as compared to placebo in healthy participants and psychiatric patients, and it had two specific aims as follows.

1. We investigated the effects of melatonergic agents on the sleepwake cycle and circadian rhythms in healthy participants.

2. We explored the effects of melatonergic agents on the sleep-wake cycle and circadian rhythms in patients with any psychiatric disorder, a population with a high prevalence of abnormalities in circadian rhythms.

\section{Searching strategies}

We searched for articles having "melatonergic agent-related keywords" AND "circadian rhythm-related keywords" AND "randomized controlled trial-related keywords" in their title and abstract. The search strategies comprised a combination of Medical Subject Headings (MeSH) or their equivalent (where available), keywords, truncations, and Boolean operators. The detailed search strategy is shown in the Supplementary Table 2. An electronic search was performed on EMBASE, PubMed, Web of Science, Cumulative Index to Nursing and Allied Health Literature (CINAHL), and Cochrane Library. All articles that were published from January 1980 to May 2020 were included.

\section{Study selection}

Firstly, duplicated articles were removed electronically. Then, articles obtained by the search strategies were manually selected with the following methods. The inclusion criteria for articles were as follows: 1) a study of the influences of melatonergic agents on melatonin rhythm and sleep-wake cycle in healthy participants and in patients with psychiatric disorders, 2) RCT, 3) the age range from 18 to 65 years, and 4) data on internal rhythms, such as sleep-wake cycle and circadian melatonin rhythm. The exclusion criteria for articles were as follows: 1) contents irrelevant to the topic, 2) work in animals or cell models, 3) patients with dementia, neurological disorders, organic brain damages, autism, or intellectual disability, 4) patients with medical conditions known to affect 


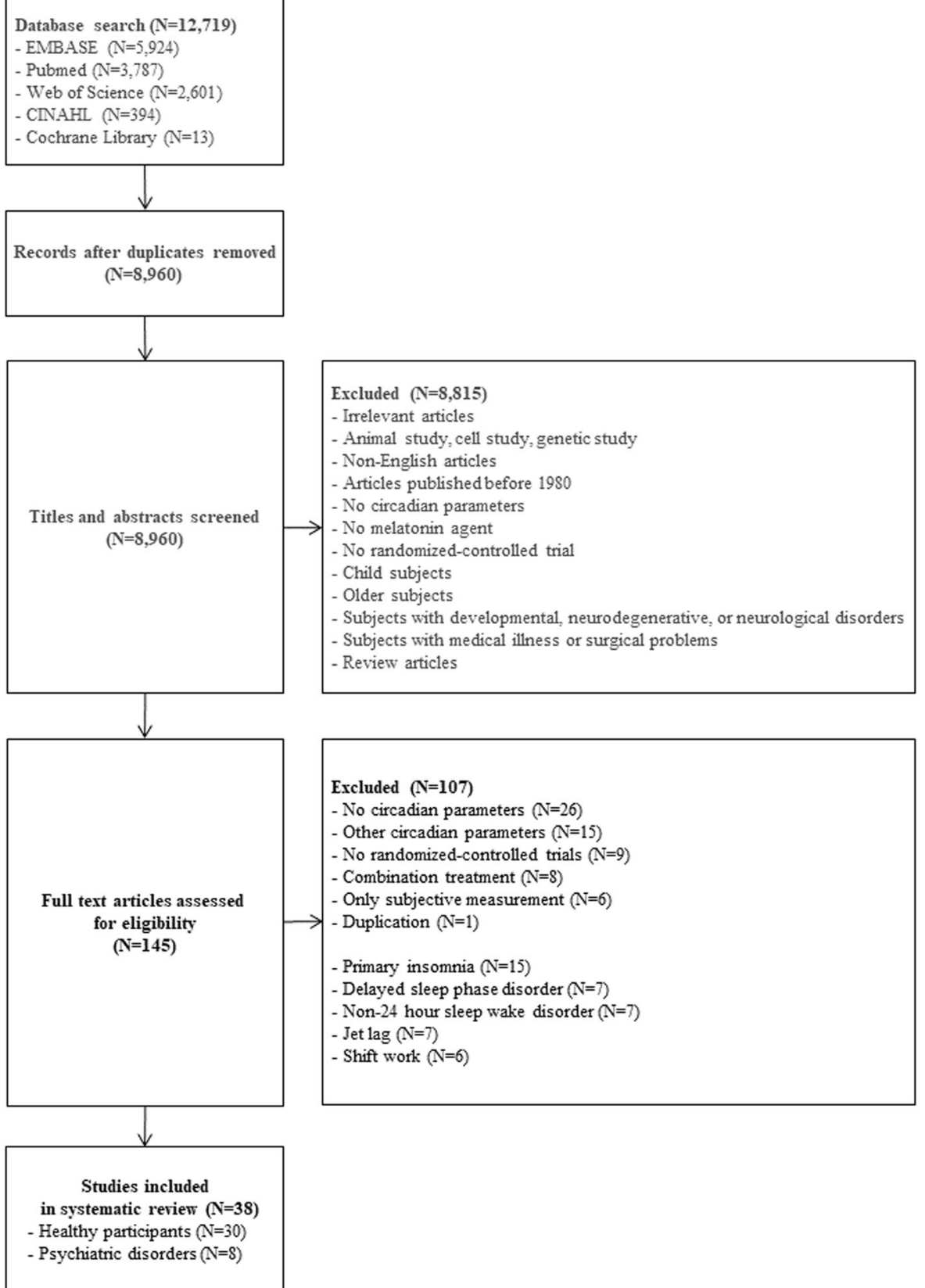

Fig. 1 Flow chart of study selection. $N$ Number.

circadian rhythms (e.g., cancer, surgery), 5) individuals undergoing pregnancy or lactation, 6) reports written by other languages except English, and 7) articles published before January 1, 1980.

The titles and abstracts of articles in a potential eligibility list were independently read by two authors (EM, OL) in order to evaluate the inclusion and exclusion criteria. Articles which met the exclusion criteria by both raters were removed from the potential eligible list. Full-texts of the remaining articles in the potential eligible list were independently read by two authors (EM, OL) in order to evaluate their eligibility. If there was any disagreement, we had a consensus meeting with a third review author (TP). References in eligible review articles were additionally evaluated by two authors (EM, OL) in order to find new articles (Fig. 1).

\section{Quality assessment}

The quality assessments of RCTs were used by the Cochrane risk of bias tool [52]. Two authors (EM, OL) completed the quality assessment for each article independently. Disagreements were solved by the consensus meeting with a third review author (TP). The quality assessments of all included studies were described in Supplementary Table 3.

\section{Data extraction}

Two authors (EM, OL) independently extracted data from the included studies (Tables 1,2). If there was any disagreement, we discussed with a third member (TP) of the review team and finalized decisions. Structured forms were used for data extraction on the following contents: authors, publication year, country, study design, principal diagnosis of participants, agent used, sex, sample size, age range, drop-out, dosing time, duration of intervention, outcome measures, and main findings.

\section{Data synthesis}

The meta-analysis of this study used the standardized mean differences (SMD) between comparative groups with $95 \%$ confidence interval $(95 \% \mathrm{Cl})$. When comparative data in multi-arm trials were used, the splitting method of shared groups was applied in order to maintain the characteristics of each 


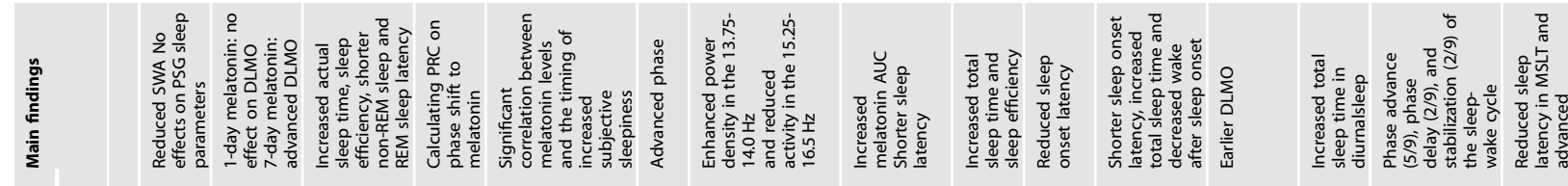

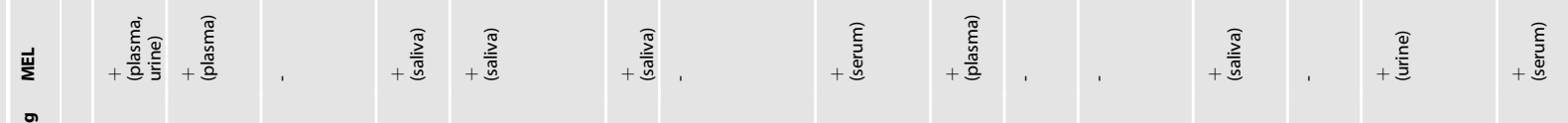

$\frac{1}{3}$

II 11\|\|

1

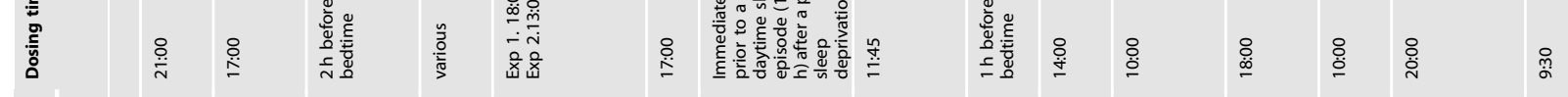

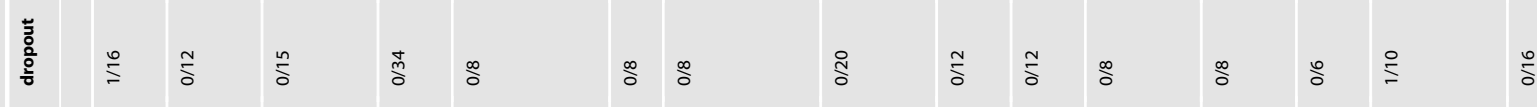

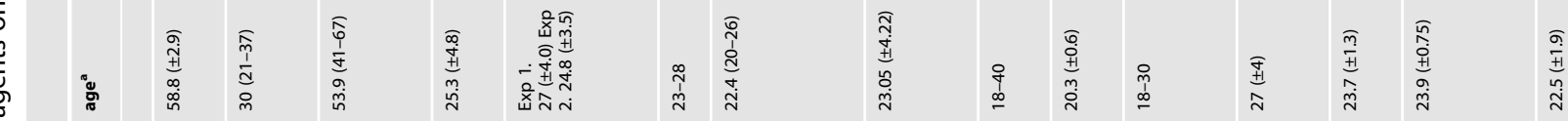

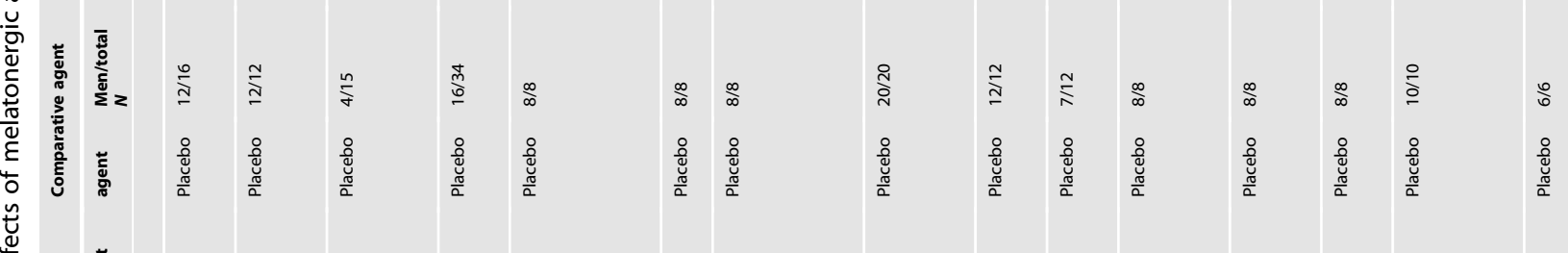

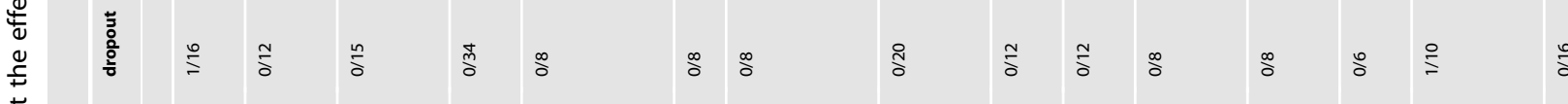

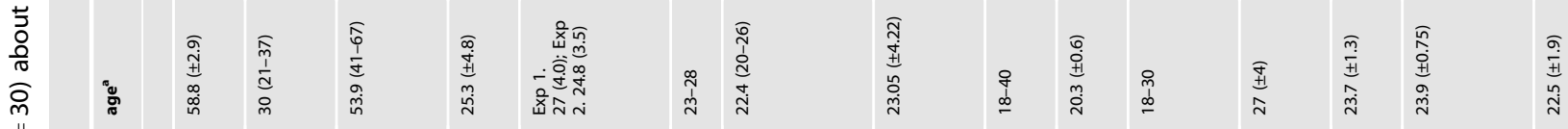

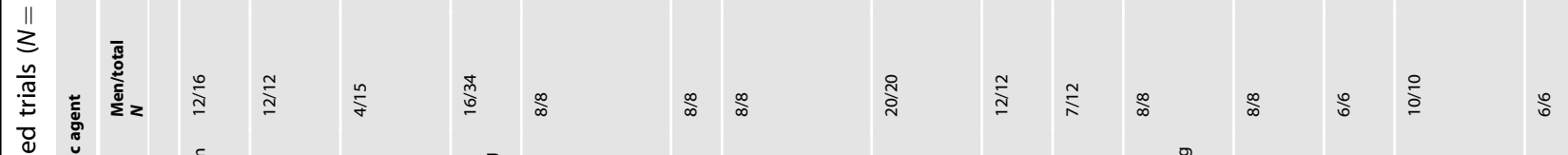

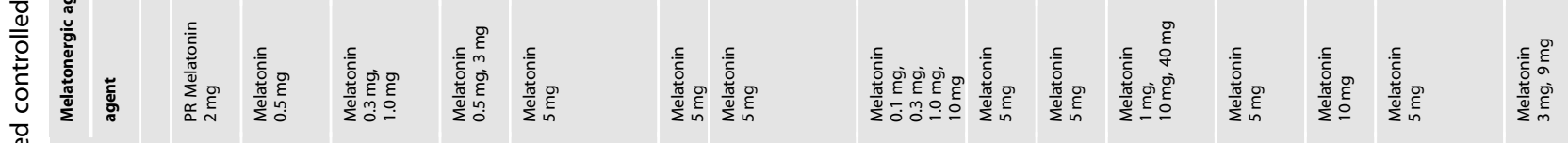

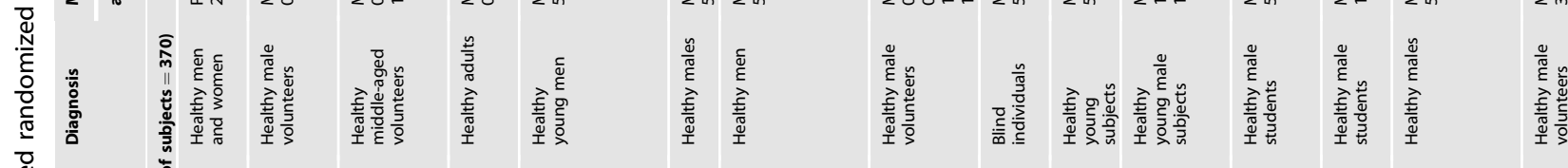

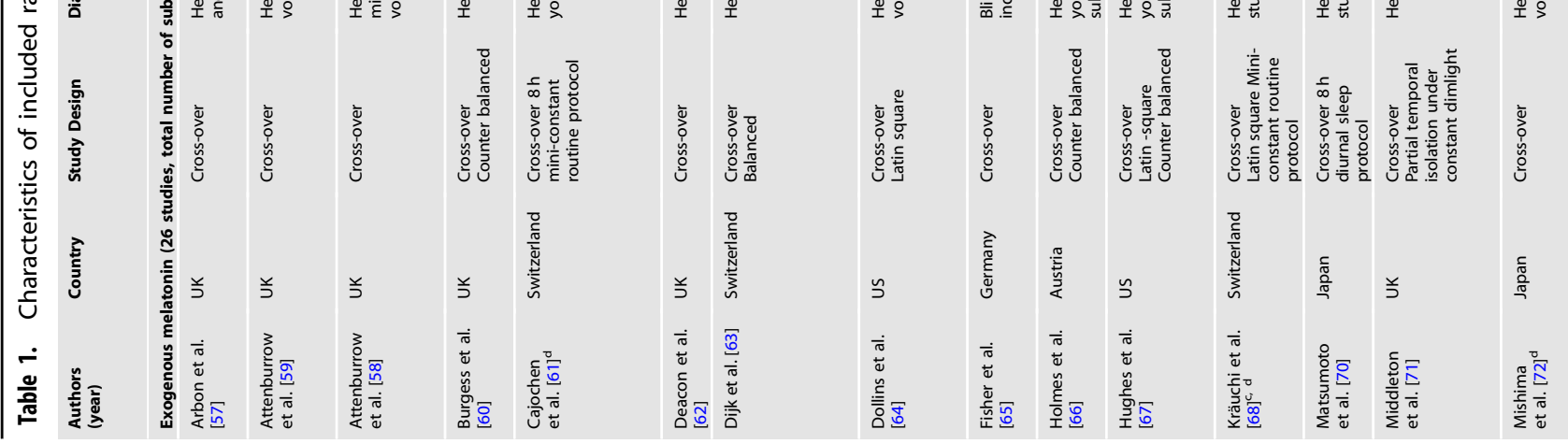




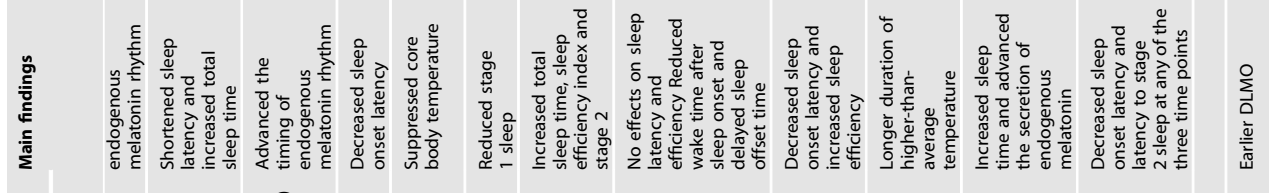

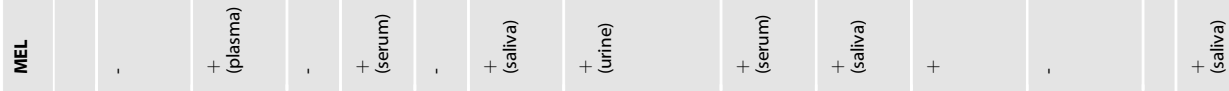

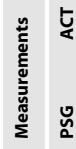

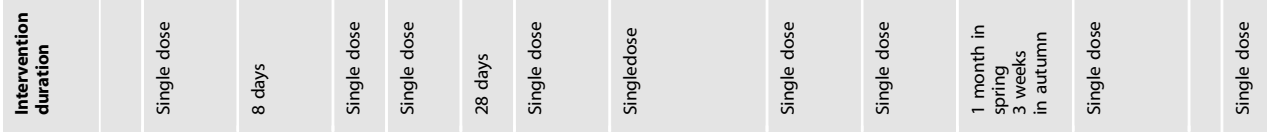

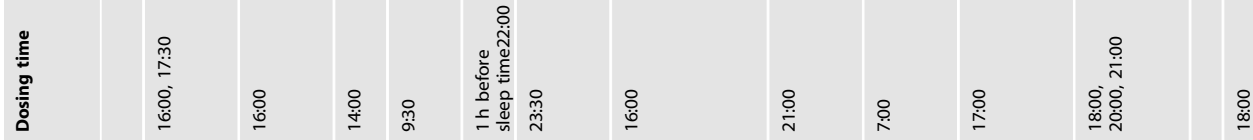

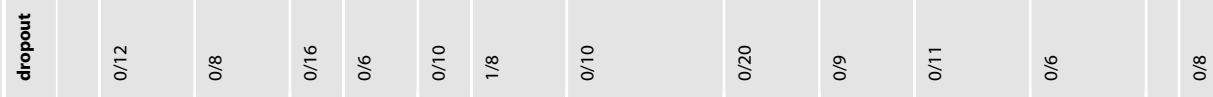

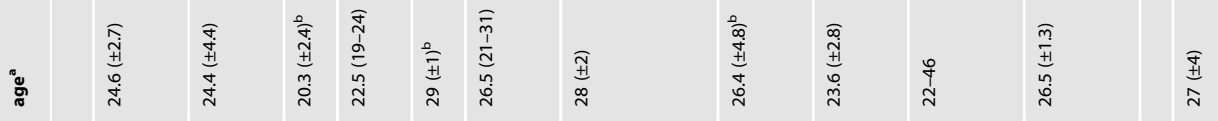

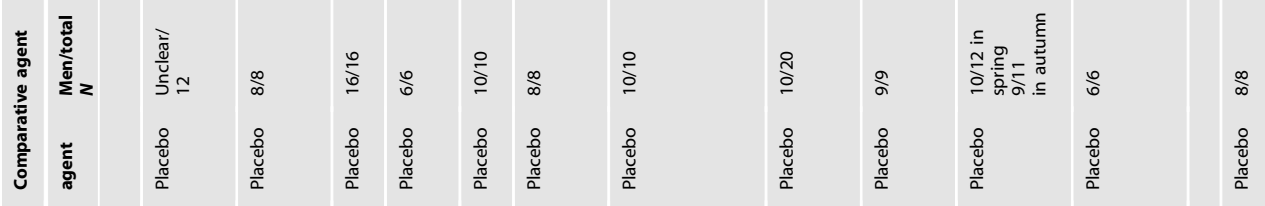

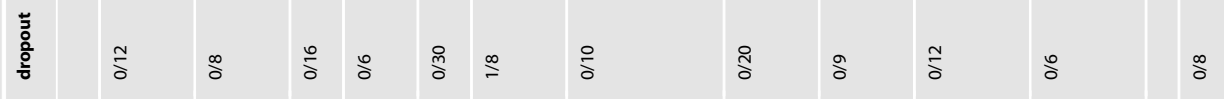

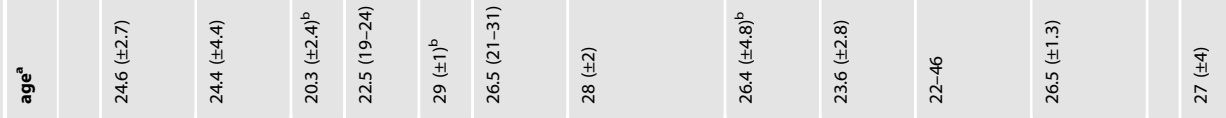

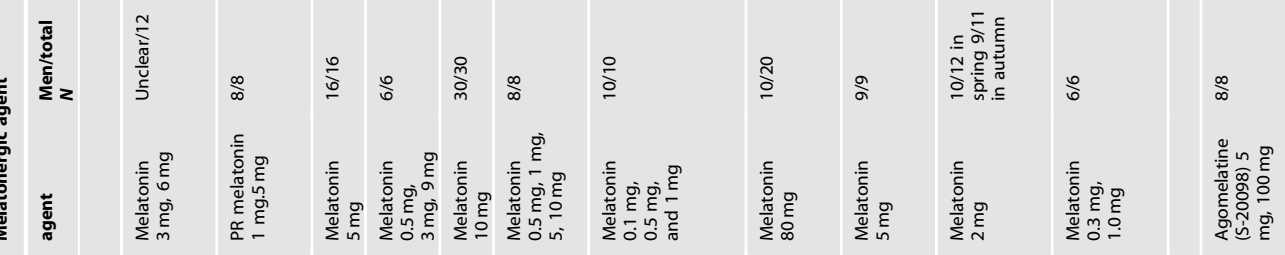

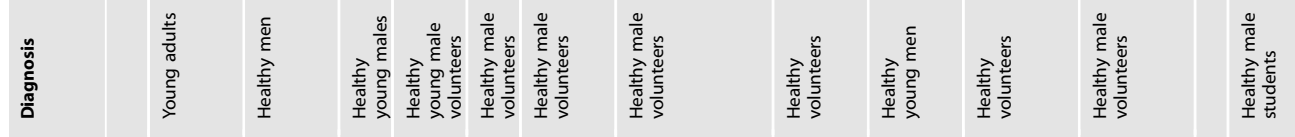

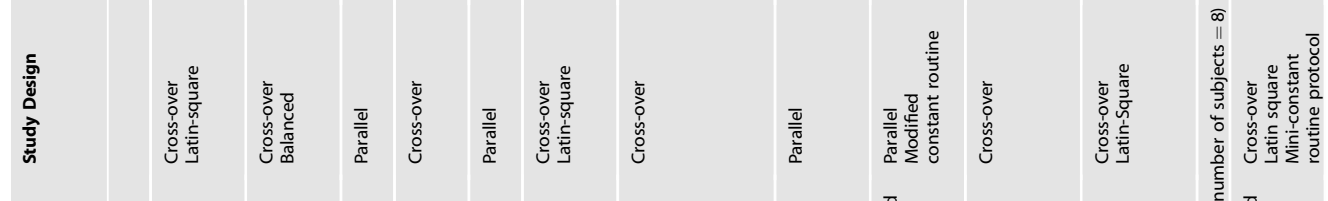

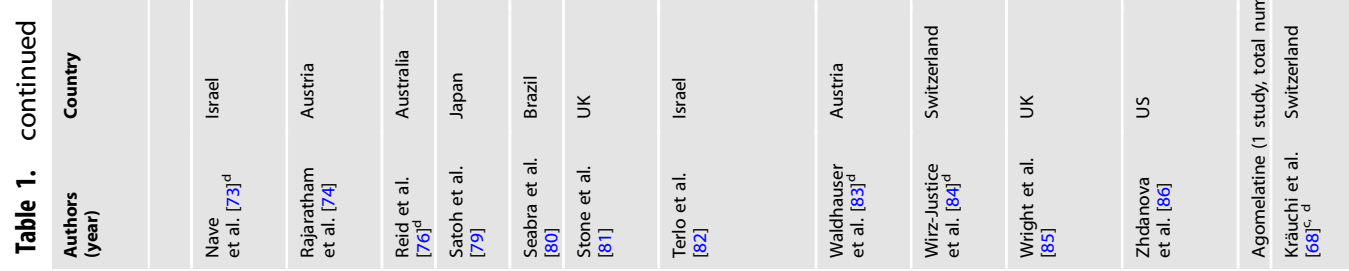



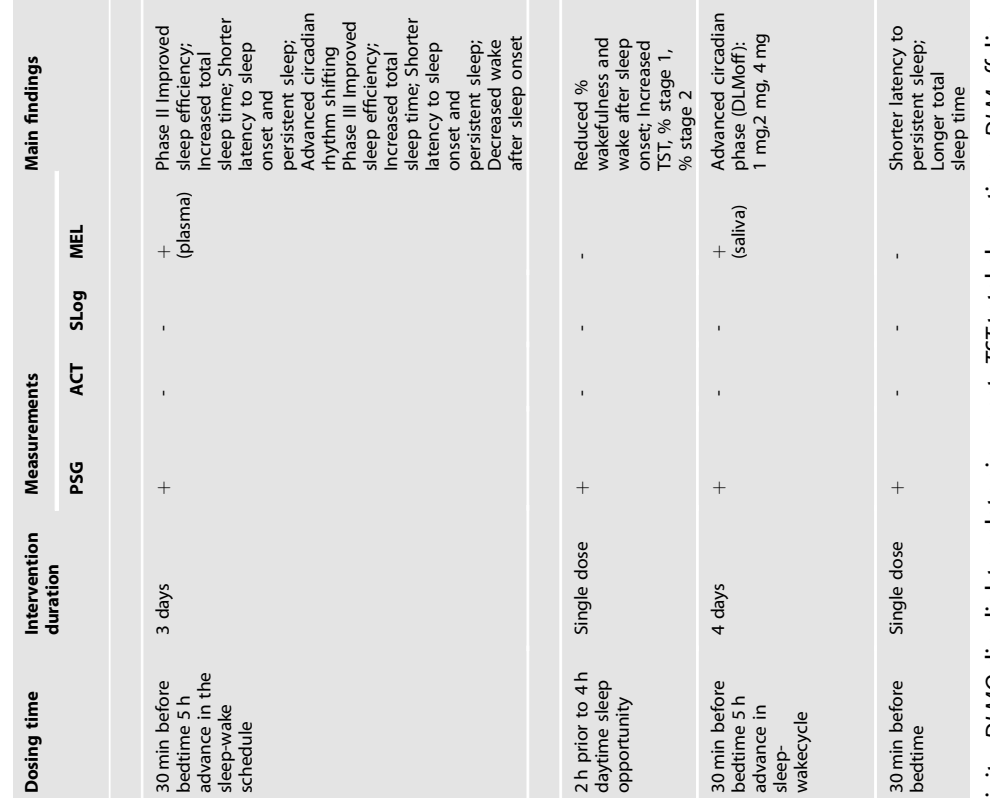

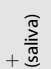

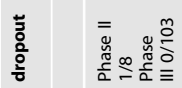

:

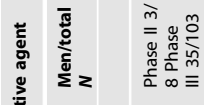

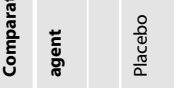

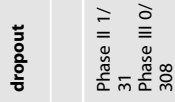

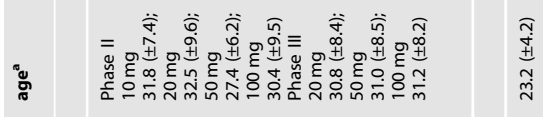

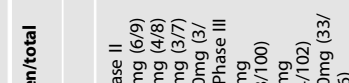

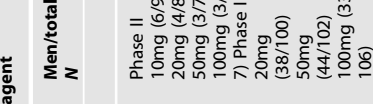

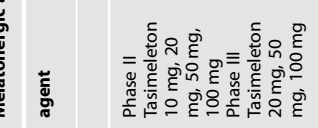

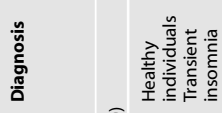

夏

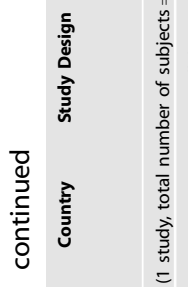

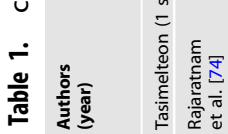

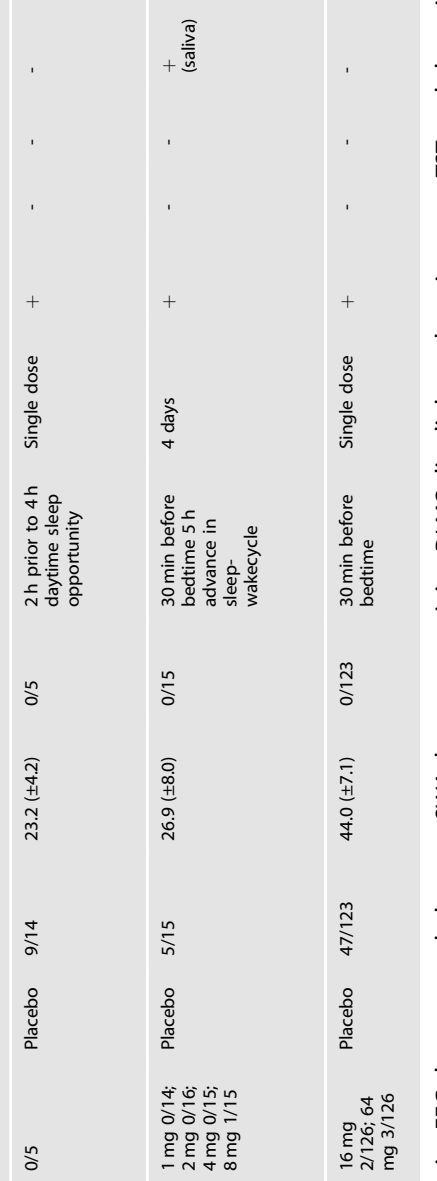

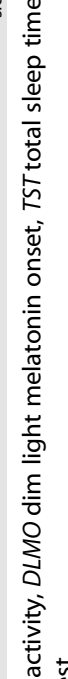

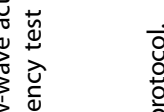

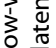

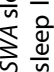

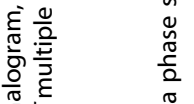

告

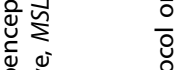

造产

迹妾

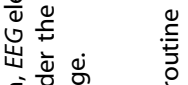

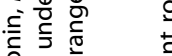

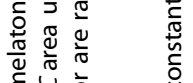

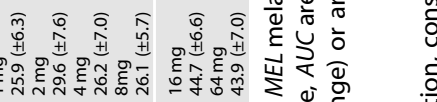

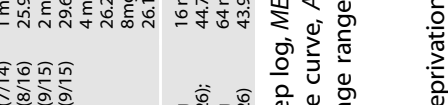

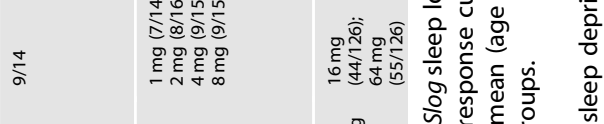

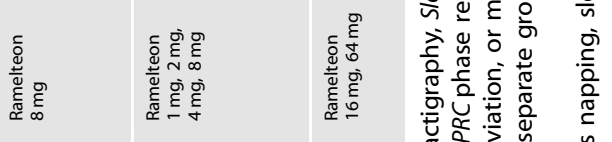

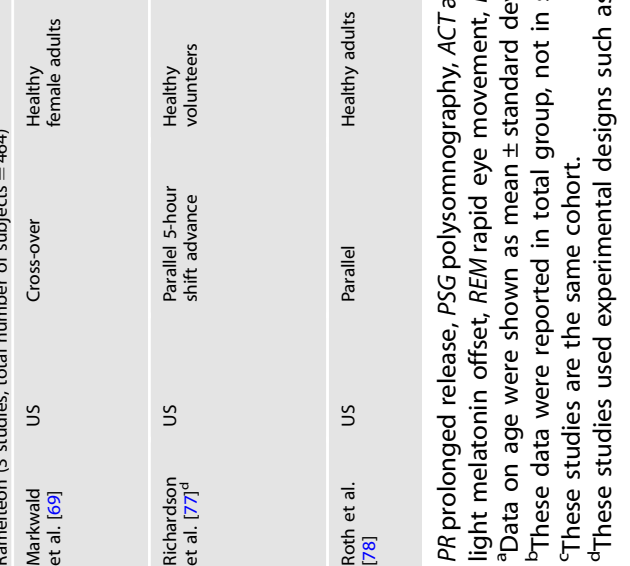




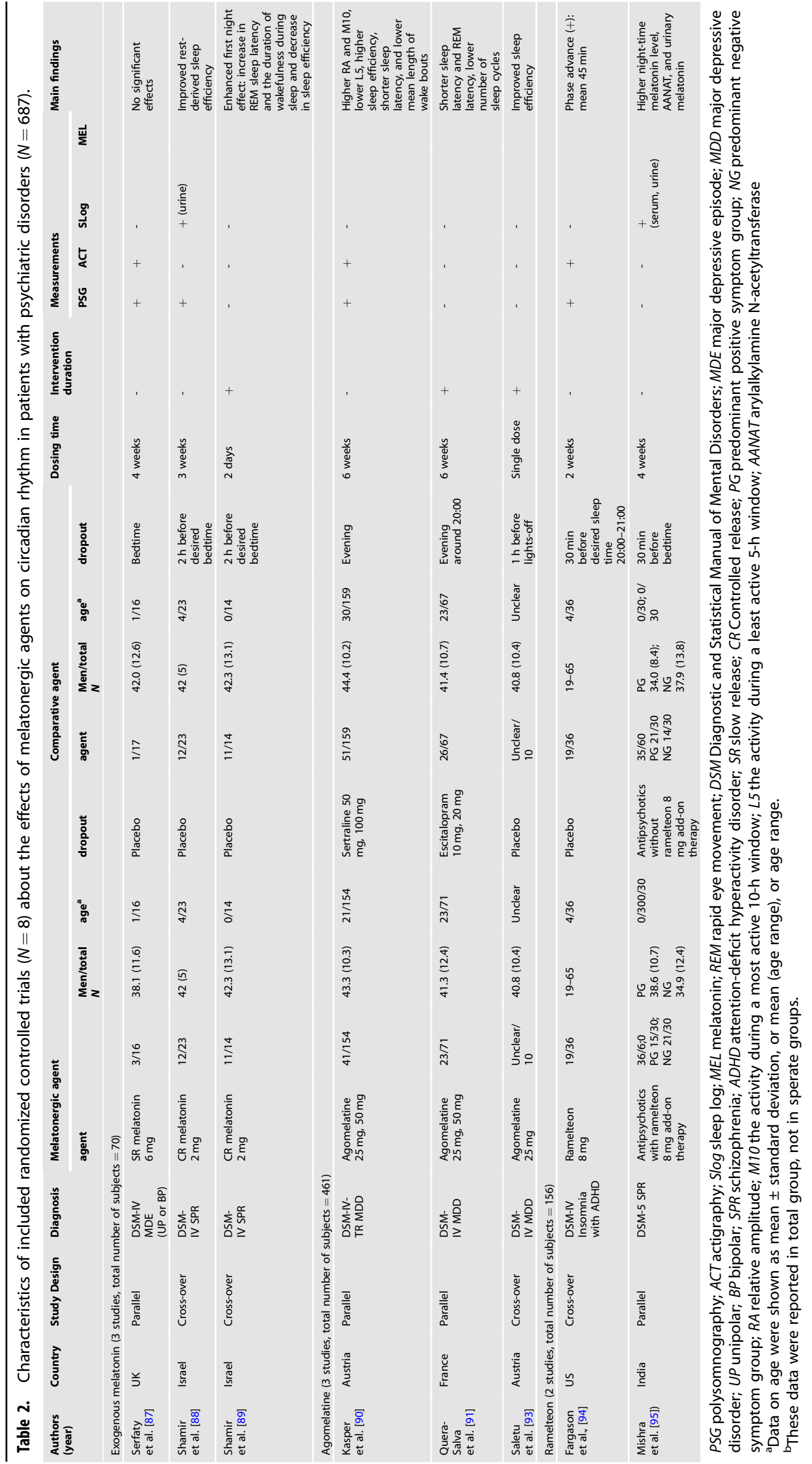


arm [53]. Based on RCTs using exogenous melatonin in healthy participants, meta-ANOVA (analysis of variance) according to the dosing time and the dosage were performed. Additionally, studies using a melatonergic agonist as well as exogenous melatonin were compared using meta-ANOVA. The heterogeneity of the results of meta-analysis was evaluated with an $l^{2}$ statistics (a low level of $<25 \%$; a moderate level of $25-50 \%$; a high level of $>50 \%$ ) [54]. When indicating significant heterogeneity based on the $p$ value of heterogeneity test and $l^{2}$ statistics (>50\%: a high level of heterogeneity), a random effect model was adopted [54-56]. Sensitivity analysis was performed by omitting one individual study at a time. Potential publication bias was evaluated with the linear regression test of funnel plots. A two tailed $p$-value less than 0.05 was considered as of a statistical significance. All the statistical analyses were performed by using R version 4.0 .5 with the "meta" package for meta-analysis.

\section{RESULTS \\ Study selection}

The original search strategy retrieved 12,719 studies, after which 3759 duplicate studies were excluded (Fig. 1). Next, after screening the titles and abstracts according to the eligibility criteria by two independent reviewers (EM, OL), 8815 studies were excluded. Two independent reviewers (EM, OL) further evaluated a total of 145 studies by reading the full-text articles, and 65 of them were excluded. Finally, we identified 80 eligible studies and excluded 42 articles which were not related to the topic. Thus, in this systematic review, 30 studies on healthy participants $(N=1294)$ and 8 studies on patients $(N=687)$ with psychiatric disorders were addressed.

\section{Current evidence on effects of melatonergic agents in healthy participants}

The 30 RCTs on effects of melatonergic agents in healthy participants were selected as shown in Table 1 [57-86]. These studies administered exogenous melatonin (26/30, 86.7\%), agomelatine $(1 / 30,3.3 \%)$, ramelteon $(3 / 30,10 \%)$, and tasimelteon (1/ $30,3.3 \%$ ). All the RCTs including exogenous melatonin, agomelatine, ramelteon, and tasimelteon reported significant effects on at least one of parameters on sleep-wake cycle or circadian melatonin rhythm. However, the effect sizes of melatonergic agents varied according to dosage and dosing time, respectively.

\section{The results of meta-analysis on RCTs using exogenous melatonin in healthy participants}

The effects of exogenous melatonin on sleep parameters in healthy participants were compared according to the dosing time and the dosage using meta-ANOVA (Fig. 2A, B). In comparing efficacy according to dosing time, administration of exogenous melatonin at 18:00 h and 20:00 h significantly decreased SOL (Fig. 2A). According to dosage, relatively low dosages such as 0.3 $\mathrm{mg}$ and $1 \mathrm{mg}$ significantly shortened SOL, while relatively high dosages such as $2 \mathrm{mg}$ and $5 \mathrm{mg}$ did not show a significant effect on SOL (Fig. 2B). Using exogenous melatonin $5 \mathrm{mg}$ at an hour before the bedtime also significantly increased sleep efficiency (SE) (Supplementary Fig. S1A, B). There were no significant effects of exogenous melatonin on TST (Supplementary Fig. S2A, B) or WASO (Supplementary Fig. S3A, B), with the exception of one study using exogenous melatonin $5 \mathrm{mg}$ at 1 -h before bedtime which significantly increased TST (Supplementary Fig. S2A, B). Sensitivity analysis showed that the results of meta-analysis were not changed after removing any one of the analyzed data. When classifying included studies according to heterogeneity, the number of included studies was limited to evaluate small study effects or potential publication bias.

\section{Comparison of RCTs using melatonergic agents on sleep parameters in healthy participants}

In order to compare the effect size of these studies according to the melatonergic agent, meta-ANOVA was performed for RCTs which reported the same sleep parameters. In analysis of metaANOVA, exogenous melatonin and tasimelteon significantly shortened SOL (Fig. 3) and improved SE (Supplementary Fig. S4) in healthy participants. The effect sizes on SOL with exogenous melatonin and tasimelteon were similar (SMD: melatonin -0.505 vs. tasimelteon -0.499; see Fig. 3). Meanwhile, the effect size of tasimelteon on SE was relatively large as compared to that of exogenous melatonin (SMD, melatonin 0.332 vs tasimelteon 0.528 ) (Supplementary Fig. S4). In addition, ramelteon and tasimelteon significantly increased TST in healthy participants, with no effect from exogenous melatonin on TST (Supplementary Fig. S5). The effect size of tasimelteon was relatively large as compared to that of ramelteon (SMD: ramelteon 0.329 vs tasimelteon 0.526 ; see Supplementary Fig. S5). Tasimelteon significantly decreased WASO (SMD: tasimelteon -0.372), with no effect from exogenous melatonin or ramelteon on WASO (Supplementary Fig. S6). Sensitivity analysis showed unchanged results after removing any one of the analyzed data. The limited number of included studies did not allow us to evaluate small study effects or potential publication bias.

\section{Current evidence on effects of melatonergic agents in patients with psychiatric disorders}

A total of eight RCTs using melatonergic agents examined the effects on parameters of sleep-wake cycle or circadian melatonin rhythms in patients with psychiatric disorders (Supplementary Table 4). Given the methodological differences and limited number of reports, we first describe results from individual studies. Three RCTs used exogenous melatonin in psychiatric patients [87-89]. In one RCT with 19 schizophrenia patients, controlled-release melatonin $2 \mathrm{mg}$ showed significant improvement in SE as compared to placebo [88]. Another RCT examined the first-night effect in PSG under the unfamiliar sleeping environment in 14 patients with schizophrenia [89]. The first night effect indicates sleep disturbances such as a decreased sleep efficiency, an increasedSOL, and increased awakening due to vigilance in an unfamiliar sleeping condition. This study showed that controlled-release melatonin $2 \mathrm{mg}$ worsened sleep states, such as a longer REM sleep latency, a lower SE, and an increased WASO in patients with schizophrenia, as compared to placebo. In contrast, a third RCT with two parallel groups including 33 patients with a major depressive episode (MDD or $\mathrm{BD})$ reported no significant impact on sleep parameters as measured with wrist actigraphy between slow-release melatonin $6 \mathrm{mg}$ and placebo [87].

Three RCTs described the effects of agomelatine in psychiatric patients [90-92]. One RCT described the effects on sleep parameters from actigraphy in 313 patients with MDD, divided to groups with agomelatine or sertraline. They reported that patients treated with agomelatine $25 \mathrm{mg}$ and $50 \mathrm{mg}$ for 6 weeks showed a higher M10 (the activity during the most active 10-h period per day), a lower $L 5$ (the activity during the least active 5-h period per day), a higher relative amplitude, a shorter SOL, a higher SE, a lower mean length of wake bouts for each night than patients on sertraline treatment [90]. Another RCT comparing the effects of agomelatine and escitalopram on sleep parameters as assessed with PSG in 138 patients with MDD observed that agomelatine $25 \mathrm{mg}$ and $50 \mathrm{mg}$ for 6 weeks significantly reduced sleep latency as well as REM latency, and decreased the number of sleep cycles as compared to escitalopram $10 \mathrm{mg}$ or $20 \mathrm{mg}$ [91]. In another RCT with ten patients having MDD, agomelatine $25 \mathrm{mg}$ also shortened SOL, improved SE, and increased TST [93].

There were two RCTs on the effects of ramelteon in psychiatric patients $[94,95]$. One RCT in 120 patients with schizophrenia on antipsychotics reported that ramelteon $8 \mathrm{mg}$ as add-on medication significantly increased the night-time melatonin, serum arylalkylamine $\mathrm{N}$-acetyltransferase (AANAT), and urinary 6MTas levels as compared to only antipsychotics without the add-on 
A

Study

Dosing time $=18: 00$

Zndanova et al (1995)_0.3mg_18.00

Zndanova et al(1995)_1mg_18:00

Fixed effect model

Heterogeneily $i^{2}=0 \%, z^{2}=0, \rho=0.95$

Dosing_time $=20: 00$

Zndanova et al (1995) 0.3mg 20.00

Zndanova et al (1995)_1mg_20.00

Fixed effect model

Random effects model

Heterogeneity $I^{2}=0 \%, t^{2}=0, \rho=0.97$

Dosing time $=21: 00$

Zndanova et al (1995) $0.3 \mathrm{mg} 21.00$

Zndanova et al (1995)_ $1 \mathrm{mg} 2100$

Arbon et al (2015)_2mg_21:00

Fixed effect mode

Random effects model

Heterogenetly, $r^{2}=0 \%, t^{2}=0, p=0.45$

Dosing_time $=2 \mathrm{~h}$ before bed time Amenburrow et al (1996) $03 \mathrm{mg} 2 \mathrm{~h}$ before BT Amenburrow es al (1996) 1mg_h before BT Amenburrow et al( 1996$)$

Fixed effect model

Random effects model
Heterogeneity $l^{2}=0 \%, t^{2}=0, p=0.78$

Dosing time $=1 \mathrm{~h}$ before bed time Fisher et al (2003) $5 \mathrm{mg}$. $1 \mathrm{~h}$ before BT

Fixed effect model

Random effects model

Heterponenety net appicatice

Fixed effect model

Random effects model

Heterogenety. $I^{2}=0 \%, r^{2}=0, \rho=061$

Residual heterogenety. $I^{2}=0 \%, \rho=0.89$
Random effects mode!

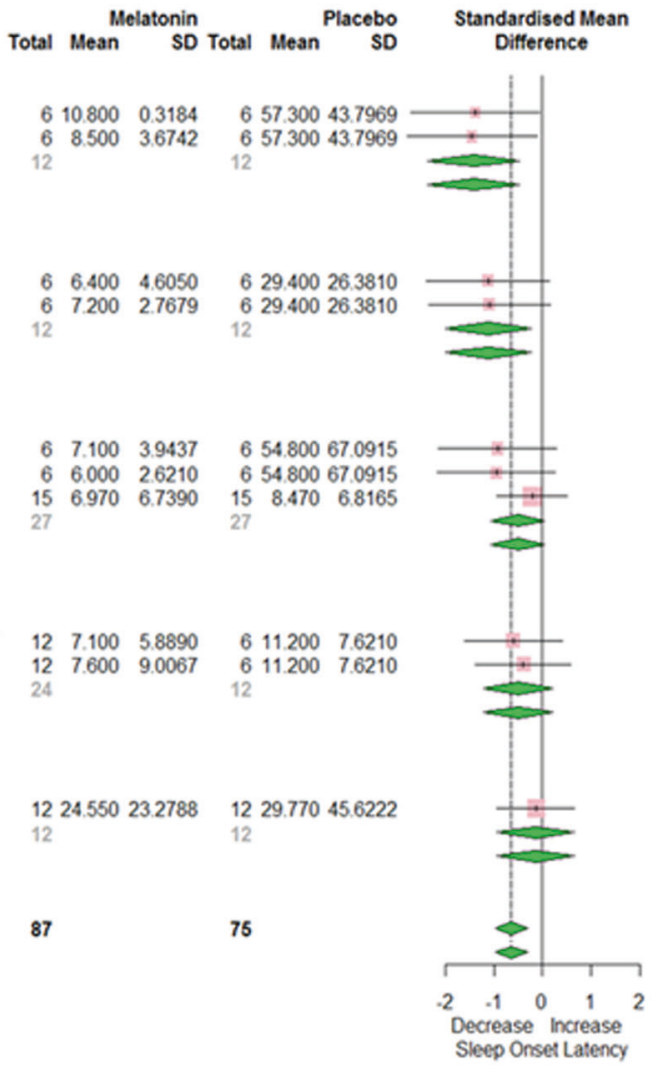

B

Study

Dosage $=0.3 \mathrm{mg}$

Attenburrow et al (1996) $0.3 \mathrm{mg} 2 \mathrm{~h}$ before BT

Zhdanova et al.(1995) $0.3 \mathrm{mg} 18.00$

Zhdanova et al (1995) $0.3 \mathrm{mg} 20.00$

Zhdanova et al (1995)_0.3mg_21.00

Fixed effect model

Random effects model

Heterogenety. $I^{2}=0 \%, \tau^{2}=0,0=081$

Dosage $=1 \mathrm{mg}$

Attenburrow et al (1996) _ $1 \mathrm{mg}$. $2 \mathrm{~h}$ before BT

Zhdanova et al (1995) 1mg 1800

Zhdanova et al (1995)_1mg_20.00

Zhdanova et al.(1995)_1mg_21:00

Fixed effect model

Random effects mode!

Heterogenetity $i^{2}=0 \%, \tau^{2}=0, \rho=0,63$

Dosage $=2 \mathrm{mg}$

Arbon et al (2015)_2mg_21.00

Fixed effect mode

Random effects mode:

fieterogenetry not apolicable

Dosage $=5 \mathrm{mg}$

Fisher et al (2003)_5mg_1h_before_BT

Fixed effect model

Random effects model

Heterogeneily. not applicable

Fixed effect model

Random effects model

Heterogenety $I^{2}=0 \%, t^{2}=0, p=0.61$

Residual heterogenety, $I^{2}=0 \%, p=0.85$

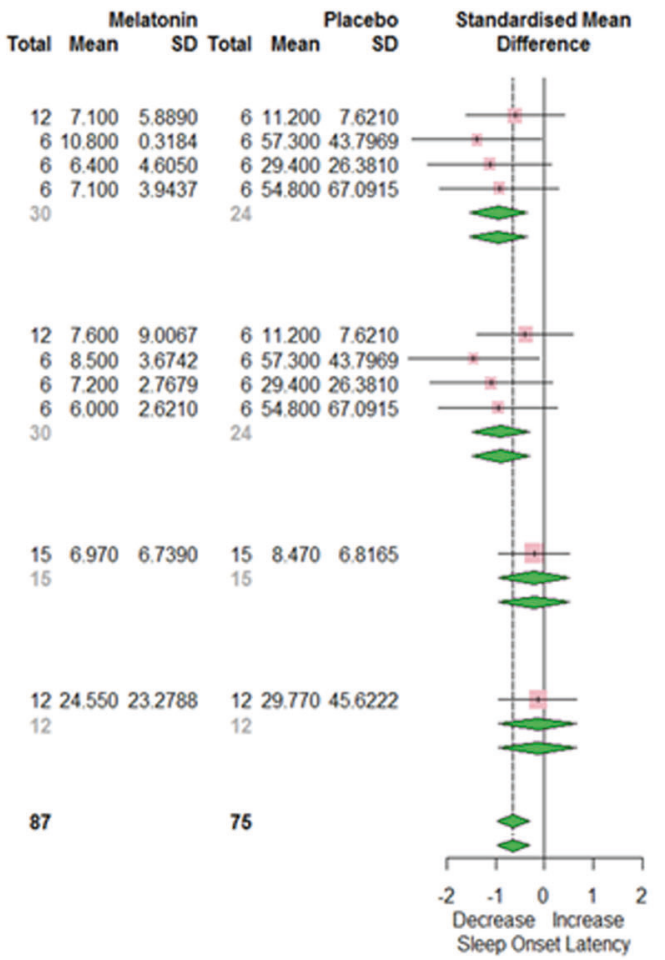

SMD

Weight Weight

$-1.386[-2.704 ;-0.068] \quad 6.2 \% \quad 6.2 \%$

$-1.449[-2.784 ;-0.115] \quad 6.1 \% \quad 6.1 \%$

$1.417[-2.355 ;-0.479] \quad 12.3 \% \quad 12.3 \%$

$1.121[-2378,0.136] \quad 68 \% \quad 6.8 \%$

$1.093[-2.344 ; 0.158] \quad 6.9 \% \quad 6.9 \%$

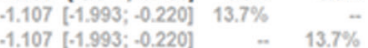

$.0 .927[.2 .145 ; 0.292] \quad 7.3 \% \quad 7.3 \%$

$0.949[-2.172,0.274] \quad 7.2 \% \quad 7.2 \%$

$0.215[-0.933,0.503] \quad 21.0 \% \quad 21.0 \%$

$0.511[-1.063 ; 0.041] 35.5 \%$

$-0.511[-1.063 ; 0.041]+35.5 \%$

$.0 .603[-1.608,0.402] \quad 10.7 \% \quad 10.7 \%$

$0.399[-1.390,0.592] \quad 11.0 \% \quad 11.0 \%$

$-0.499(1.205 ; 0.206]-21.7 \%$

$0.499[-1.205 ; 0.206]$

$21.7 \%$

$0.139[-0.940 ; 0.662] \quad 16.8 \% \quad 16.8 \%$

$0.139[-0.940 ; 0.662] 16.8 \%$

$0.139[-0.940 ; 0.662]$

$16.8 \%$

$-0.639[-0.968 ;-0.310] 100.0 \%$

$-0.639[-0.968 ;-0.310] \quad-\quad 100.0 \%$

SMD Weight Weight

$0.603[-1.608 ; 0.402] 10.7 \%$

$-1.386[-2.704 ;-0.068] \quad 6.2 \% \quad 6.2 \%$

. $121 \quad[-2.378 ; 0.136] \quad 6.8 \%-6.8 \%$

$\begin{array}{rrr}-0.950[-1.540 ;-0.360] & 7.3 \% & 7.3 \%\end{array}$

$-0.950[-1.540 ;-0.360] \quad \ldots \quad 31.0 \%$

$0.399[-1.390,0.592] \quad 11.0 \% \quad 11.0 \%$

$1.449[-2.784 ;-0.115] \quad 6.1 \% \quad 6.1 \%$

$-1.093[-2.344 ; 0.158] \quad 6.9 \% \quad 6.9 \%$

$0.949[-2.172,0.274] \quad 7.2 \% \quad 7.2 \%$

$0.884[-1.472 ;-0.296] \quad 31.2 \%$

$0.884[-1.472 ;-0.296]-31.2 \%$

$0215[-0.933 ; 0.503] 21.0 \%$

$0.215[-0.933 ; 0.503] 21.0 \%$

$-0.215[-0.933 ; 0.503]+21.0 \%$

$.0 .139[-0.940,0.662] \quad 16.8 \% \quad 16.8 \%$ $-0.139[-0.940 ; 0.662] 16.8 \%$

$0.139[-0.940 ; 0.662] \quad[-$

$16.8 \%$

$-0.639[-0.968 ;-0.310] 100.0 \%$

$-0.639[-0.968 ;-0.310] \quad-\quad 100.0 \%$

Fig. 2 The synthesized standardized mean difference (SMD) of 10 comparative datasets. The pooled SMD in healthy subjects showed that exogenous melatonin significantly decreased SOL compared to placebo. Administration of exogenous melatonin at 18:00 and 20:00 significantly decreased SOL (A). Low dosages significantly shortened SOL (B). BT bedtime, SD standard deviation. 


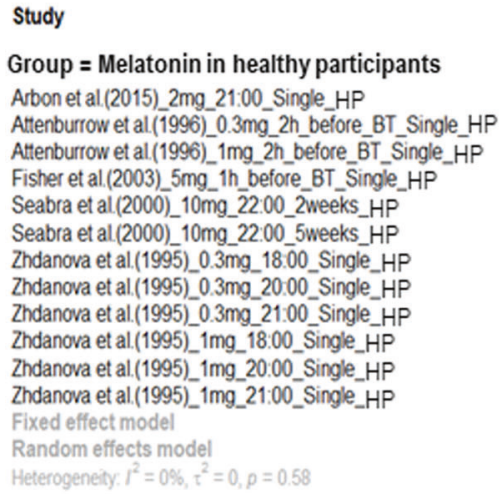

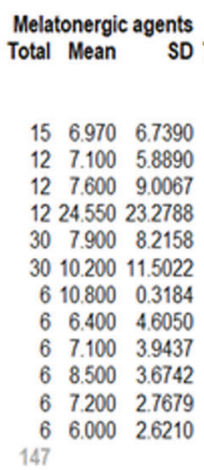

147

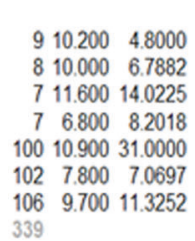

1526900250000 1533.30031 .9000 1926.00025 .4000

49

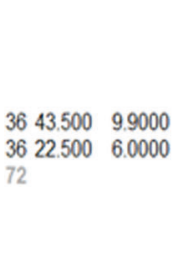

607

SD Total Mean

$15 \quad 8.470-68165$ $\begin{array}{lll}6 & 11.200 & 7.6210\end{array}$ $611.200 \quad 7.6210$ 1229.77045 .6222 $\begin{array}{ll}10 & 9.700 \quad 7.2732\end{array}$ 1012.80027 .1956 657.30043 .7969 629.40026 .3810 654.80067 .0915 657.30043 .7969 629.40026 .3810 654.80067 .0915

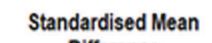
Differed Mean

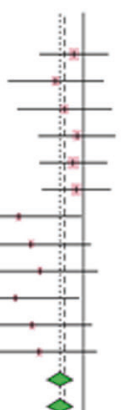
SMD

Weight Weight $95 \% \cdot \mathrm{Cl}$ (fixed) (random)

$-0.215[-0.933 ; 0.503] \quad 4.0 \%$ $-0.603[-1.608 ; 0.402]-21 \% \quad 3.9 \%$ $-0.399[-1.390 ; 0.592] \quad 2.1 \% \quad 3.9 \%$ $-0.139[-0.940 ; 0.662] \quad 3.2 \% \quad 4.6 \%$ $-0.220[-0.938 ; 0.497] \quad 4.0 \% \quad 5.0 \%$ $-0.153[-0.870 ; 0.563] \quad 4.1 \% \quad 5.0 \%$ $-1.386[-2.704 ;-0.068] \quad 1.2 \% \quad 2.9 \%$ $-1.121[-2.378 ; 0.136] \quad 1.3 \% \quad 3.1 \%$ $-0.927 \quad[-2.145 ; 0.292] \quad 1.4 \% \quad 3.2 \%$ $-1.449[-2.784,-0.115] \quad 1.2 \% \quad 2.9 \%$ $-1.093[-2.344 ; 0.158] \quad 1.3 \% \quad 3.1 \%$ $-0.949[-2.172 ; 0.274] \quad 1.4 \% \quad 3.2 \%$ $-0.505[-0.781 ;-0.229] 27.4 \%$ $-0.505[-0.781 ;-0.229] \quad \ldots \quad 45.7 \%$

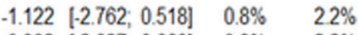
$-0.982[.2 .627 ; 0.663] \quad 0.8 \% \quad 2.2 \%$ $-0.566[-2.175 ; 1.044] \quad 0.8 \% \quad 2.3 \%$ $-1.103[-2.815 ; 0.609] \quad 0.7 \% \quad 2.1 \%$ $-0.311[-0.706,0.084] \quad 13.3 \% \quad 6.2 \%$ $\begin{array}{llll}-0.311 & {[-0.706,0.084]} & 13.3 \% & 6.2 \% \\ -0.597[-0.992 ;-0.202] & 13.4 \% & 6.3 \%\end{array}$ $-0.488[-0.871 ;-0.106] \quad 14.2 \% \quad 6.3 \%$ $-0.499[-0.716 ;-0.281] \quad 44.0 \%$ $-0.499[-0.716 ;-0.281] \quad-\quad 27.6 \%$

$0.139[-0.566 ; 0.844] \quad 4.2 \% \quad 5.0 \%$ $0.152[-0.554 ; 0.857] \quad 4.2 \% \quad 5.0 \%$ $-0.462[-1.107 ; 0.184] \quad 5.0 \% \quad 5.3 \%$ $-0.082[-0.476 ; 0.313]-13.4 \%$ $0.080[-0.487 ; 0.327] \quad-\quad 15.3 \%$ 1628.90024 .3000 51

000

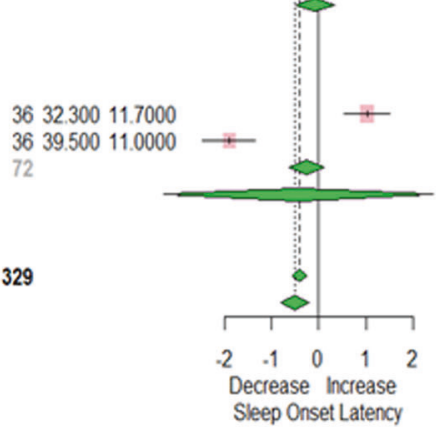

$1.022[0.529 ; 1.515] \quad 8.6 \% \quad 5.9 \%$ $-1.898[-2.459,-1.337] \quad 6.6 \% \quad 5.6 \%$ $-0.249[-0.619 ; 0.121] \quad 15.2 \%$ $-0.435[-3.297 ; 2.427] \quad-\quad 11.5 \%$

$-0.407[-0.551 ;-0.262] 100.0 \%$ $-0.511[-0.805 ;-0.216] \quad-100.0 \%$

Fig. 3 Meta-ANOVA on efficacy of exogenous melatonin and melatonergic agents on sleep onset latency (SOL) in healthy participants and psychiatric patients. The standardized mean differences (SMD) of 24 comparative datasets were synthesized. The pooled SMD in healthy participants showed that exogenous melatonin and tasimelteon significantly decreased SOL compared to placebo. The pooled SMD of exogenous melatonin and ramelteon in psychiatric patients did not show change of SOL compared to placebo. HP healthy participants, UP unipolar, BP bipolar, ADHD attention deficit hyperactivity disorder, SPR schizophrenia, BT bedtime, SD standard deviation.

ramelteon [95]. Increase of serum AANAT concentration known as melatonin rhythm-generating enzyme [96] was consistent with melatonin secretion. Another RCT in 36 patients with insomnia and adult ADHD showed that patients after two weeks of treatment with ramelteon $8 \mathrm{mg}$ had a significantly earlier sleep midpoint as measured with actigraphy than those on placebo [94].

\section{The results of meta-analysis on RCTs using exogenous} melatonin and melatonergic agents in psychiatric patients When synthesizing findings in psychiatric patients, there were no significant effects of exogenous melatonin and ramelteon on SOL (Fig. 3), SE (Supplementary Fig. S4), TST (Supplementary Fig. S5), and WASO (Supplementary Fig. S6). Due to the small number and methodological differences of studies, the meta-analyses according to dosing and timing were not performed. Even though some studies showed significant effects of agomelatine on sleep parameters, these studies were not included in the meta-analysis due to use of comparative antidepressants instead of placebo or limited information (only poster abstract available). The main findings of these studies not included in meta-ANOVA were summarized in Supplementary Table 4. Of the two studies using exogenous melatonin included in meta-analysis, one study used SR melatonin $6 \mathrm{mg}$ at bedtime, and the other study used CR melatonin $2 \mathrm{mg}$ at $2 \mathrm{~h}$ before desired bedtime. These dosages and dosing time of exogenous melatonin were similar to those that did not show the significant findings in healthy participants (Fig. 2). While large-scale studies in healthy participants showed significant findings on sleep-wake parameters, studies administrating ramelteon in psychiatric patients showed a similar finding with a small sample size (each group's $N=36$, cross-over design).

\section{DISCUSSION}

This systematic review summarized the effects of melatonergic agents for correcting disrupted sleep-wake and circadian rhythms in healthy and psychiatric participants. Trials on healthy participants demonstrated that specific melatonergic supplements and agonists advanced the phase of sleep-wake and circadian rhythms that were 
originally within the normal range. The meta-analysis of studies with sleep-wake cycle parameters showed that the exogenous melatonin and melatonergic agonists significantly advanced the phase of circadian melatonin rhythm [59, 60,62,68, 74, 77, 85]. Given an advancing effect of melatonin on circadian parameters [68, 74, 94], shortening sleep latency might be caused by a chronobiotic effect such as a phase advance. Alternatively, these effects of exogenous melatonin and melatonergic agents on sleep parameters could be mediated by a hypnotic effect and/or sleep consolidation [16, 49, 97]. Particularly, the co-occurrence of a decreased SOL and an advanced DLMO in the delayed sleep phase syndrome suggest the possibility that shortening of sleep latency might be related to the advance of circadian rhythms such as measured with DLMO [3].

In psychiatric populations, the prevalence of phase delay and disrupted circadian rhythms is high. Despite the need for evidence-based treatments for phase delay and disrupted circadian rhythms specifically in psychiatric populations, our main finding for this population was that trials with melatonergic agents and with a focus on circadian parameters are very limited and methodologically too variable for conclusions. Interestingly, the effect of melatonergic agents seemed similar to that of healthy participants [88-91, 94]. Studies using agomelatine in psychiatric patients showed an improving effect on sleep-wake parameters $[90,91,93]$, similar to the results in healthy participants.

Meanwhile, studies with psychiatric patients reported stabilizing effects on circadian and sleep-wake rhythms, such as sleep-wake cycle or melatonin rhythm [88, 90, 91, 93-95], similar to the results in healthy participants. Among the three trials in patients with schizophrenia, one RCT with exogenous melatonin for three weeks improved sleep-wake cycle [88], and another RCT with add-on ramelteon medication enhanced circadian melatonin rhythm [95]. Among the four trials in patients with MDD, one RCT using slow-release melatonin $6 \mathrm{mg}$ with major depressive episode including bipolar depression did not show any significant finding on sleep-wake parameters as measured with actigraphy and sleep log [87]. While three RCTs including two large MDD cohorts showed a consistent positive effect of agomelatine on sleep-wake cycle, two studies compared agomelatine to selective serotonin reuptake inhibitors (SSRIs) instead of placebo. When considering the evidence that SSRI can change sleep pattern [98], these findings should be cautiously interpreted. A trial with ADHD also reported that ramelteon advanced the timing of sleep-wake cycle [94]. For other potential agents to correct circadian rhythms, in our previous review, we found that antipsychotics actually might be more harmful and rhythm disrupting [99]. The negative impact of selective serotonergic agents has been recognized earlier [98], and the use of benzodiazepines has contraindications [100]. We conclude that melatonergic agents have shown potential efficacy in and are the most promising agents for correcting disrupted sleep-wake and circadian rhythms. Given the clinical need for evidence-based treatments to correct circadian rhythms, further trials with proper inclusion criteria and outcome measures for circadian rhythms among psychiatric patients are warranted. Limited data provides some evidence that melatonin might be less efficient on sleep-wake parameters than ramelteon or agomelatine in this patient population. Trials measuring the effects of especially agomelatine and ramelteon in different psychiatric cohorts on sleep phasing and consolidation are warranted.

Several studies have suggested that melatonergic agents can be effective as antidepressant or antimanic agent [101-103]. Given that disrupted circadian rhythms are related to mood symptoms [104], the antidepressant or antimanic effect of melatonergic agents may be at least partly be mediated through correcting disrupted circadian rhythms $[105,106]$. According to the findings of our metaanalysis, the effect of melatonergic compounds was dependent on the dosing time and dose. Based on the phase-response curve and the results of this meta-analysis, the dosing time around $3 \mathrm{~h}$ before DLMO from $18: 00 \mathrm{~h}$ to $20: 00 \mathrm{~h}$ is likely to be the best dosing time to advance phasing., and the optimal dose was small. With this timing, the effect sizes of sleep-wake parameters (SOL) were large [107109]. These results were consistent with earlier results which established the phase-response curve for shifting the phase of melatonin rhythm $[48,110]$. A small dosage of melatonin showed a bigger effect size of advancing SOL than a high dosage. A high dosage of melatonin, however, was more effective to increase SE and/or TST. Considering the differential effects of dosage according to sleep-wake parameters, the clinician has to select the proper timing and dosage depending on treatment target such as reducing SOL or increasing TST. A well-designed study that can confirm the dose-response curve for specific sleep-wake parameters is needed in the future. If confirmed, these results could guide personalized treatment.

Chronobiological and chronotherapeutic knowledge should inform methods of future trials. Optimal parameters to objectively describe the phase shifting of circadian rhythms and poor sleep consolidation are important, and they were rarely used in trials, especially for psychiatric patients. Typically, the individual rhythms were not evaluated on pre-trial basis, while the dosing time was predetermined and thus not matched with the individual rhythm. In other words, the efficacy of melatonergic agents according to the predetermined dosing time could be different on each person and the mean effect of melatonergic agents is likely to be dampened. The melatonin level could be affected by various factors such as sex, age, current mood, seasons, medications, and exposure to light [111-113] and should be better controlled for in future trials. The study design, including the compound, timing and dose, inclusion criteria, and outcome, should be suitable for the target circadian outcome. It seems that transdiagnostic psychiatric cohorts with uniform circadian inclusion criteria would work, which would make it easier to recruit larger cohorts providing clinically relevant data [114]. In these carefully characterized cohorts, more knowledge about an optimal dosing time as compared to the current individual phasing, period and target timing can be gained.

\section{Limitations}

Firstly, despite the reasonable number of original studies on healthy participants, the methodological variability reduced the number of comparable studies for the meta analysis. Nevertheless, our main findings concern results from the meta-analysis that showed a low heterogeneity based on $l^{2}$ within the included articles and a low risk of publication bias. Secondly, of the number of studies in psychiatric patients was limited, and additionally, heterogeneity of clinical diagnosis, and heterogeneity of parameters of circadian rhythms limited conclusions for this population. We found no trials in anxiety disorders, eating disorders, personality disorders, or specifically in BD. Most of the studies on the effects of melatonergic agents stick to a classic clinical study design, inclusion by diagnostic category, and mood as the main outcome. We focused on studies with objective circadian parameters and thus, excluded a number of studies with psychometric measures of insomnia or mood as outcomes.

\section{CONCLUSION}

In healthy participants, most of studies with exogeneous melatonin showed an advancing effect of circadian rhythm. Interestingly, for phase advancement an earlier time and smaller dose, but for sleep quality/consolidation a larger and later dose seemed appropriate. Exogenous melatonin and melatonergic receptor agonists could be effective in correcting disrupted circadian and sleep-wake rhythms. Large scale, well-designed randomized controlled trials in psychiatric patients are warranted. 


\section{REFERENCES}

1. Cajochen C, Krauchi K, Wirz-Justice A. Role of melatonin in the regulation of human circadian rhythms and sleep. J Neuroendocrinol. 2003;15:432-7.

2. Konakchieva R, Mitev Y, Almeida OF, Patchev VK. Chronic melatonin treatment counteracts glucocorticoid-induced dysregulation of the hypothalamicpituitary-adrenal axis in the rat. Neuroendocrinology. 1998;67:171-80.

3. van Geijlswijk IM, Korzilius HP, Smits MG. The use of exogenous melatonin in delayed sleep phase disorder: a meta-analysis. Sleep. 2010;33:1605-14.

4. Suhner A, Schlagenhauf $P$, Johnson R, Tschopp A, Steffen R. Comparative study to determine the optimal melatonin dosage form for the alleviation of jet lag. Chronobiol Int. 1998;15:655-66.

5. Spitzer RL, Terman M, Williams JBW, Terman JS, Malt UF, Singer F, et al. Jet lag: clinical features, validation of a new syndrome-specific scale, and lack of response to melatonin in a randomized, double-blind trial. Am J Psychiatry. 1999;156:1392-96.

6. Sharkey KM, Fogg LF, Eastman Cl. Effects of melatonin administration on daytime sleep after simulated night shift work. J Sleep Res. 2001;10:181-92.

7. Sadeghniiat-Haghighi K, Bahrami H, Aminian O, Meysami A, Khajeh-Mehrizi A. Melatonin therapy in shift workers with difficulty falling asleep: a randomized, double-blind, placebo-controlled crossover field study. Work-a J Prev Assess Rehabilitation. 2016;55:225-30.

8. Lockley SW, Skene DJ, James K, Thapan K, Wright J, Arendt J. Melatonin administration can entrain the free-running circadian system of blind subjects. $J$ Endocrinol. 2000;164:R1-6.

9. Sack RL, Brandes RW, Kendall AR, Lewy AJ. Entrainment of free-running circadian rhythms by melatonin in blind people. N Engl J Med. 2000;343:1070-7.

10. Auld F, Maschauer EL, Morrison I, Skene DJ, Riha RL. Evidence for the efficacy of melatonin in the treatment of primary adult sleep disorders. Sleep Med Rev. 2017;34:10-22.

11. Bonacci JM, Venci JV, Gandhi MA. Tasimelteon (Hetlioz): a new melatonin receptor agonist for the treatment of non-24-hour sleep-wake disorder. J Pharm Pr. 2015;28:473-8.

12. Rajaratnam SM, Polymeropoulos MH, Fisher DM, Roth T, Scott C, Birznieks G, et al. Melatonin agonist tasimelteon (VEC-162) for transient insomnia after sleep-time shift: two randomised controlled multicentre trials. Lancet 2009;373:482-91.

13. Polymeropoulos CM, Mohrman MA, Keefe MS, Brzezynski JL, Wang J, Prokosch LS, et al. Efficacy of Tasimelteon (HETLIOZ(R)) in the treatment of jet lag disorder evaluated in an 8-h phase advance model; a multicenter, randomized, doubleblind, placebo-controlled trial. Front Neurol. 2020;11:611.

14. Lockley SW, Dressman MA, Licamele L, Xiao C, Fisher DM, Flynn-Evans EE, et al. Tasimelteon for non-24-hour sleep-wake disorder in totally blind people (SET and RESET): two multicentre, randomised, double-masked, placebo-controlled phase 3 trials. Lancet. 2015;386:1754-64.

15. Nishimon S, Nishimon M, Nishino S. Tasimelteon for treating non-24-h sleepwake rhythm disorder. Expert Opin Pharmacother. 2019;20:1065-73.

16. Kuriyama $A$, Honda $M$, Hayashino $Y$. Ramelteon for the treatment of insomnia in adults: a systematic review and meta-analysis. Sleep Med. 2014;15:385-92.

17. Yanagihara $M$, Nakamura $M$, Usui $A$, Nishida $S$, Ito $E$, Okawa $M$, et al. The melatonin receptor agonist is effective for free-running type circadian rhythm sleep disorder: case report on two sighted patients. Tohoku J Exp Med. 2014;234:123-8.

18. Walker WH 2nd, Walton JC, DeVries AC, Nelson RJ. Circadian rhythm disruption and mental health. Transl Psychiatry. 2020;10:28.

19. Melo MCA, Abreu RLC, Linhares Neto VB, de Bruin PFC, de Bruin VMS. Chronotype and circadian rhythm in bipolar disorder: a systematic review. Sleep Med Rev. 2017;34:46-58.

20. Melo MC, Garcia RF, Linhares Neto VB, Sa MB, de Mesquita LM, de Araujo CF, et al. Sleep and circadian alterations in people at risk for bipolar disorder: a systematic review. J Psychiatr Res. 2016;83:211-9.

21. Porcu A, Gonzalez R, McCarthy MJ. Pharmacological manipulation of the circadian clock: a possible approach to the management of bipolar disorder. CNS Drugs. 2019;33:981-99.

22. Moon JH, Cho CH, Son GH, Geum D, Chung S, Kim H, et al. Advanced circadian phase in mania and delayed circadian phase in mixed mania and depression returned to normal after treatment of bipolar disorder. EBioMedicine. 2016;11:285-95.

23. Meyer N, Faulkner SM, McCutcheon RA, Pillinger T, Dijk DJ, MacCabe JH. Sleep and circadian rhythm disturbance in remitted schizophrenia and bipolar disorder: a systematic review and meta-analysis. Schizophr Bull. 2020;46:1126-43.

24. Wulff K, Dijk DJ, Middleton B, Foster RG, Joyce EM. Sleep and circadian rhythm disruption in schizophrenia. Br J Psychiatry. 2012;200:308-16.

25. Monteleone $\mathrm{P}$, Martiadis V, Maj M. Circadian rhythms and treatment implications in depression. Prog Neuropsychopharmacol Biol Psychiatry. 2011;35:1569-74.
26. Duncan WC Jr. Circadian rhythms and the pharmacology of affective illness. Pharm Ther. 1996;71:253-312.

27. Parry BL, Newton RP. Chronobiological basis of female-specific mood disorders. Neuropsychopharmacology 2001;25(5 Suppl):S102-S8.

28. Norbury R. Diurnal preference and depressive symptomatology: a meta-analysis. Sci Rep. 2021;11:12003.

29. Coogan AN, Thome J. Chronotherapeutics and psychiatry: setting the clock to relieve the symptoms. World J Biol Psychiatry. 2011;12(Suppl 1):S40-3.

30. Bertrand L, d'Ortho MP, Reynaud E, Lejoyeux M, Bourgin P, Geoffroy PA. Polysomnography in seasonal affective disorder: a systematic review and metaanalysis. J Affect Disord. 2021;292:405-15.

31. Potter GD, Skene DJ, Arendt J, Cade JE, Grant PJ, Hardie LJ. Circadian rhythm and sleep disruption: causes, metabolic consequences, and countermeasures. Endocr Rev. 2016;37:584-608.

32. Goel N, Stunkard AJ, Rogers NL, Van Dongen HP, Allison KC, O'Reardon JP, et al. Circadian rhythm profiles in women with night eating syndrome. J Biol Rhythms. 2009;2485-94.

33. Roveda E, Montaruli A, Galasso L, Pesenti C, Bruno E, Pasanisi P, et al. Restactivity circadian rhythm and sleep quality in patients with binge eating disorder. Chronobiol Int. 2018;35:198-207.

34. Linnaranta O, Bourguignon C, Crescenzi O, Sibthorpe D, Buyukkurt A, Steiger $H_{\text {, }}$ et al. Late and instable sleep phasing is associated with irregular eating patterns in eating disorders. Ann Behav Med. 2020;54:680-90.

35. Coogan AN, Baird AL, Popa-Wagner A, Thome J. Circadian rhythms and attention deficit hyperactivity disorder: the what, the when and the why. Prog Neuropsychopharmacol Biol Psychiatry. 2016;67:74-81.

36. Tonetti L, Conca A, Giupponi G, Filardi M, Natale V. Circadian activity rhythm in adult attention-deficit hyperactivity disorder. J Psychiatr Res. 2018;103:1-4.

37. Walters AS, Silvestri R, Zucconi M, Chandrashekariah R, Konofal E. Review of the possible relationship and hypothetical links between attention deficit hyperactivity disorder (ADHD) and the simple sleep related movement disorders, parasomnias, hypersomnias, and circadian rhythm disorders. J Clin Sleep Med. 2008;4:591-600.

38. McGowan NM, Goodwin GM, Bilderbeck AC, Saunders KEA. Circadian restactivity patterns in bipolar disorder and borderline personality disorder. Transl Psychiatry. 2019;9:195.

39. Kawato M, Fujita K, Suzuki R, Winfree AT. A three-oscillator model of the human circadian system controlling the core temperature rhythm and the sleep-wake cycle. J Theor Biol. 1982;98:369-92.

40. Ancoli-Israel S, Cole R, Alessi C, Chambers M, Moorcroft W, Pollak CP. The role of actigraphy in the study of sleep and circadian rhythms. Sleep. 2003;26:342-92.

41. Kushida CA, Littner MR, Morgenthaler T, Alessi CA, Bailey D, Coleman J Jr., et al. Practice parameters for the indications for polysomnography and related procedures: an update for 2005. Sleep. 2005;28:499-521.

42. Dueck A, Reis O, Bastian M, van Treeck L, Weirich S, Haessler F, et al. Feasibility of a complex setting for assessing sleep and circadian rhythmicity in a fragile $X$ cohort. Front Psychiatry. 2020;11:361.

43. Marino M, Li Y, Rueschman MN, Winkelman JW, Ellenbogen JM, Solet JM, et al. Measuring sleep: accuracy, sensitivity, and specificity of wrist actigraphy compared to polysomnography. Sleep. 2013;36:1747-55.

44. Roomkham S, Lovell D, Cheung J, Perrin D. Promises and challenges in the use of consumer-grade devices for sleep monitoring. IEEE Rev Biomed Eng. 2018;11:53-67.

45. Newell J, Mairesse O, Verbanck P, Neu D. Is a one-night stay in the lab really enough to conclude? First-night effect and night-to-night variability in polysomnographic recordings among different clinical population samples. Psychiatry Res. 2012;200:795-801.

46. van Hees VT, Sabia S, Jones SE, Wood AR, Anderson KN, Kivimaki $M$, et al. Estimating sleep parameters using an accelerometer without sleep diary. Sci Rep. 2018;8:12975.

47. Lavin-Gonzalez P, Bourguignon C, Crescenzi O, Beaulieu S, Storch KF, Linnaranta O. Inactograms and objective sleep measures as means to capture subjective sleep problems in patients with a bipolar disorder. Bipolar Disord. 2020;22:722-30.

48. Pandi-Perumal SR, Smits M, Spence W, Srinivasan V, Cardinali DP, Lowe AD, et al. Dim light melatonin onset (DLMO): a tool for the analysis of circadian phase in human sleep and chronobiological disorders. Prog Neuropsychopharmacol Biol Psychiatry. 2007;31:1-11.

49. Brzezinski A, Vangel MG, Wurtman RJ, Norrie G, Zhdanova I, Ben-Shushan A, et al. Effects of exogenous melatonin on sleep: a meta-analysis. Sleep Med Rev. 2005;9:41-50.

50. Van Geijlswijk IM, Korzilius HPLM, Smits MG. The use of exogenous melatonin in delayed sleep phase disorder: a meta-analysis. Sleep. 2010;33:1605-14.

51. Ferracioli-Oda E, Qawasmi A, Bloch MH. Meta-analysis: melatonin for the treatment of primary sleep disorders. Focus (Am Psychiatr Publ). 2018;16:113-8. 
52. Higgins JP, Altman DG, Gotzsche PC, Juni P, Moher D, Oxman AD, et al. The Cochrane Collaboration's tool for assessing risk of bias in randomised trials. BMJ 2011;343:d5928.

53. Rucker G, Cates CJ, Schwarzer G. Methods for including information from multiarm trials in pairwise meta-analysis. Res Synth Methods. 2017;8:392-403.

54. Higgins JP, Thompson SG, Deeks JJ, Altman DG. Measuring inconsistency in meta-analyses. BMJ 2003;327:557-60.

55. Melsen WG, Bootsma MC, Rovers MM, Bonten MJ. The effects of clinical and statistical heterogeneity on the predictive values of results from meta-analyses. Clin Microbiol Infect. 2014;20:123-9.

56. Tani H, Takasu S, Uchida H, Suzuki T, Mimura M, Takeuchi H. Factors associated with successful antipsychotic dose reduction in schizophrenia: a systematic review of prospective clinical trials and meta-analysis of randomized controlled trials. Neuropsychopharmacology. 2020;45:887-901.

57. Arbon EL, Knurowska M, Dijk DJ. Randomised clinical trial of the effects of prolonged-release melatonin, temazepam and zolpidem on slow-wave activity during sleep in healthy people. J Psychopharmacol. 2015;29:764-76.

58. Attenburrow MEJ, Cowen PJ, Sharpley AL. Low dose melatonin improves sleep in healthy middle-aged subjects. Psychopharmacology. 1996;126:179-81.

59. Attenburrow MEJ, Dowling BA, Sargent PA, Sharpley AL, Cowen PJ. Melatonin phase advances circadian rhythm. Psychopharmacology. 1995;121:503-5.

60. Burgess HJ, Revell VL, Molina TA, Eastman $\mathrm{Cl}$. Human phase response curves to three days of daily melatonin: $0.5 \mathrm{mg}$ Versus $3.0 \mathrm{mg}$. J Clin Endocrinol Metab. 2010;95:3325-31.

61. Cajochen C, Kräuchi K, Von Arx MA, Möri D, Graw P, Wirz-Justice A. Daytime melatonin administration enhances sleepiness and theta/alpha activity in the waking EEG. Neurosci Lett. 1996;207:209-13.

62. Deacon S, English J, Arendt J. Acute phase-shifting effects of melatonin associated with suppression of core body temperature in humans. Neurosci Lett. 1994; 178:32-4.

63. Dijk DJ, Roth C, Landolt HP, Werth E, Aeppli M, Achermann P, et al. Melatonin effect on daytime sleep in men: suppression of EEG low frequency activity and enhancement of spindle frequency activity. Neurosci Lett. 1995;201:13-6.

64. Dollins AB, Zhdanova IV, Wurtman RJ, Lynch HJ, Deng MH. Effect of inducing nocturnal serum melatonin concentrations in daytime on sleep, mood, body temperature, and performance. Proc Natl Acad Sci USA. 1994;91:1824-8.

65. Fischer S, Smolnik R, Herms M, Born J, Fehm HL. Melatonin acutely improves the neuroendocrine architecture of sleep in blind individuals. J Clin Endocrinol Metab. 2003;88:5315-20.

66. Holmes AL, Gilbert SS, Dawson D. Melatonin and zopiclone: the relationship between sleep propensity and body temperature. Sleep 2002;25:301-6.

67. Hughes RJ, Badia P. Sleep-promoting and hypothermic effects of daytime melatonin administration in humans. Sleep. 1997;20:124-31.

68. Kräuchi K, Cajochen C, Möri D, Graw P, Wirz-Justice A. Early evening melatonin and S-20098 advance circadian phase and nocturnal regulation of core body temperature. Am J Physiol - Regulatory Integr Comp Physiol. 1997;272: R1178-R88. 4 41-4.

69. Markwald RR, Lee-Chiong TL, Burke TM, Snider JA, Wright KP Jr. Effects of the melatonin MT-1/MT-2 agonist ramelteon on daytime body temperature and sleep. Sleep. 2010;33:825-31.

70. Matsumoto $M$. The hypnotic effects of melatonin treatment on diurnal sleep in humans. Psychiatry Clin Neurosci. 1999;53:243-5.

71. Middleton B, Arendt J, Stone BM. Complex effects of melatonin on human circadian rhythms in constant dim light. J Biol Rhythms. 1997;12:467-77.

72. Mishima K, Satoh K, Shimizu T, Hishikawa Y. Hypnotic and hypothermic action of daytime-administered melatonin. Psychopharmacology. 1997;133:168-71.

73. Nave R, Peled R, Lavie P. Melatonin improves evening napping. Eur J Pharmacol. 1995;275:213-6.

74. Rajaratnam SM, Polymeropoulos MH, Fisher DM, Roth T, Scott C, Birznieks G, et al. Melatonin agonist tasimelteon (VEC-162) for transient insomnia after sleep-time shift: two randomised controlled multicentre trials. Lancet. 2009; 373 North American Edition:482-91.

75. Rajaratnam SMW, Dijk DJ, Middleton B, Stone BM, Arendt J. Melatonin phaseshifts human circadian rhythms with no evidence of changes in the duration of endogenous melatonin secretion or the 24-hour production of reproductive hormones. J Clin Endocrinol Metab. 2003;88:4303-9.

76. Reid K, Van Den Heuvel C, Dawson D. Day-time melatonin administration: effects on core temperature and sleep onset latency. J Sleep Res. 1996;5:150-4.

77. Richardson GS, Zee PC, Wang-Weigand S, Rodriguez L, Peng X. Circadian phaseshifting effects of repeated ramelteon administration in healthy adults. J Clin Sleep Med. 2008;4:456-61.

78. Roth T, Stubbs C, Walsh JK. Ramelteon (TAK-375), a selective MT1/MT2-receptor agonist, reduces latency to persistent sleep in a model of transient insomnia related to a novel sleep environment. Sleep. 2005;28:303-7.
79. Satoh K, Mishima K. Hypothermic action of exogenously administered melatonin is dose-dependent in humans. Clin Neuropharmacol. 2001;24:334-40.

80. Seabra WDV, Bignotto M, Pinto LR, Tufik S. Randomized, double-blind clinical trial, controlled with placebo, of the toxicology of chronic melatonin treatment. J Pineal Res. 2000;29:193-200.

81. Stone BM, Turner C, Mills SL, Nicholson AN. Hypnotic activity of melatonin. Sleep. 2000;23:663-9.

82. Terlo L, Laudon M, Tarasch R, Schatz T, Caine YG, Zisapel N. Effects of low doses of melatonin on late afternoon napping and mood. Biol Rhythm Res. 1997;28:2-15.

83. Waldhauser F, Saletu B, Trinchard-Lugan I. Sleep laboratory investigations on hypnotic properties of melatonin. Psychopharmacology. 1990;100:222-6.

84. Wirz-Justice A, Werth E, Renz C, Muller S, Krauchi K. No evidence for a phase delay in human circadian rhythms after a single morning melatonin administration. J Pineal Res. 2002;32:1-5.

85. Wright J, Aldhous M, Franey C, English J, Arendt J. The effects of exogenous melatonin on endocrine function in man. Clin Endocrinol. 1986;24:375-82.

86. Zhdanova IV, Wurtman RJ, Lynch HJ, Ives JR, Dollins AB, Morabito C, et al. Sleepinducing effects of low doses of melatonin ingested in the evening. Clin Pharmacol Ther. 1995;57:552-8.

87. Serfaty MA, Osborne D, Buszewicz MJ, Blizard R, Raven PW. A randomized double-blind placebo-controlled trial of treatment as usual plus exogenous slow-release melatonin $(6 \mathrm{mg})$ or placebo for sleep disturbance and depressed mood. Int Clin Psychopharmacol. 2010;25:132-42.

88. Shamir E, Laudon M, Barak Y, Anis Y, Rotenberg V, Elizur A, et al. Melatonin improves sleep quality of patients with chronic schizophrenia. J Clin Psychiatry. 2000;61:373-7.

89. Shamir E, Rotenberg VS, Laudon M, Zisapel N, Elizur A. First-night effect of melatonin treatment in patients with chronic schizophrenia. J Clin Psychopharmacol. 2000;20:691-4.

90. Kasper S, Hajak G, Wulff K, Hoogendijk WJ, Montejo AL, Smeraldi E, et al. Efficacy of the novel antidepressant agomelatine on the circadian rest-activity cycle and depressive and anxiety symptoms in patients with major depressive disorder: a randomized, double-blind comparison with sertraline. J Clin Psychiatry. 2010;71:109-20.

91. Quera-Salva MA, Hajak G, Philip P, Montplaisir J, Keufer-Le Gall S, Laredo J, et al. Comparison of agomelatine and escitalopram on nighttime sleep and daytime condition and efficacy in major depressive disorder patients. Int Clin Psychopharmacol. 2011;26:252-62.

92. Wulff K, Laigle L, Hajak G, Kasper S. Preliminary findings of the rest-activity cycles in patients with major depression following agomelatine and sertraline treatment. Eur Neuropsychopharmacol. 2012;22:S264.

93. Saletu B, Anderer P, Saletu M, Rosales-Rodriguez S, Saletu-Zyhlarz G. Acute effects of agomelatine on sleep and awakening in major depression: Controlled polysomnographic and psychometric studies. J Sleep Res. 2012;21:25.

94. Fargason RE, Gamble K, Avis KT, Besing RC, Cherry Jackson W, Cates ME, et al. Ramelteon for insomnia related to attention-deficit/ hyperactivity disorder (ADHD). Psychopharmacol Bull. 2011;44:32-53.

95. Mishra A, Maiti R, Mishra BR, Jena M, Nath S, Sahu P. Effect of add-on ramelteon therapy on sleep and circadian rhythm disruption in patients with schizophrenia: a randomized controlled trial. Eur Neuropsychopharmacol. 2020;31:109-18.

96. Chattoraj A, Liu T, Zhang LS, Huang Z, Borjigin J. Melatonin formation in mammals: in vivo perspectives. Rev Endocr Metab Disord. 2009;10:237-43.

97. Pinto LR Jr., Seabra Mde L, Tufik S. Different criteria of sleep latency and the effect of melatonin on sleep consolidation. Sleep. 2004;27:1089-92.

98. Wichniak A, Wierzbicka A, Walecka M, Jernajczyk W. Effects of antidepressants on sleep. Curr Psychiatry Rep. 2017;19:63.

99. Moon E, Lavin P, Storch KF, Linnaranta O. Effects of antipsychotics on circadian rhythms in humans: a systematic review and meta-analysis. Prog Neuropsychopharmacol Biol Psychiatry. 2021;108:110162.

100. Campbell R, Chabot I, Rousseau B, Bridge D, Nicol G, Meier G. Understanding the unmet needs in insomnia treatment: a systematic literature review of real-world evidence. Int J Neurosci. 2021. https://doi.org/10.1080/00207454.2021.1995383. [Online ahead of print].

101. Singh SP, Singh V, Kar N. Efficacy of agomelatine in major depressive disorder: meta-analysis and appraisal. Int J Neuropsychopharmacol. 2012;15:417-28.

102. Kishi T, Nomura I, Sakuma K, Kitajima T, Mishima K, Iwata N. Melatonin receptor agonists-ramelteon and melatonin-for bipolar disorder: a systematic review and meta-analysis of double-blind, randomized, placebo-controlled trials. Neuropsychiatr Dis Treat. 2019;15:1479-86.

103. Kishi T, Nishiyama H, Kimura $Y$, Sadaka T, Terada A, Tatsumi $Y$, et al. Melatonin receptor agonists for bipolar mania: a systematic review and meta-analyses of double-blind randomized placebo-controlled trials. Bipolar Disord. 2021;23:301-2. 
104. Lyall LM, Wyse CA, Graham N, Ferguson A, Lyall DM, Cullen B, et al. Association of disrupted circadian rhythmicity with mood disorders, subjective wellbeing, and cognitive function: a cross-sectional study of 91105 participants from the UK Biobank. Lancet. Psychiatry 2018;5:507-14.

105. Quera Salva MA, Hartley S. Mood disorders, circadian rhythms, melatonin and melatonin agonists. J Cent Nerv Syst Dis. 2012;4:15-26.

106. Laudon M, Frydman-Marom A. Therapeutic effects of melatonin receptor agonists on sleep and comorbid disorders. Int J Mol Sci. 2014;15:15924-50.

107. Krauchi K, Wirz-Justice A. Circadian clues to sleep onset mechanisms. Neuropsychopharmacology. 2001;25:S92-6. 5 Suppl.

108. Saxvig IW, Wilhelmsen-Langeland A, Pallesen S, Vedaa O, Nordhus IH, Sorensen $\mathrm{E}$, et al. Objective measures of sleep and dim light melatonin onset in adolescents and young adults with delayed sleep phase disorder compared to healthy controls. J Sleep Res. 2013;22:365-72.

109. Murray JM, Phillips AJK, Magee M, Sletten TL, Gordon C, Lovato N, et al. Sleep regularity is associated with sleep-wake and circadian timing, and mediates daytime function in delayed sleep-wake phase disorder. Sleep Med. 2019;58:93-101.

110. Burgess $\mathrm{HJ}$, Revell VL, Eastman $\mathrm{Cl}$. A three pulse phase response curve to three milligrams of melatonin in humans. J Physiol. 2008;586:639-47.

111. Beck-Friis J, von Rosen D, Kjellman BF, Ljunggren JG, Wetterberg L. Melatonin in relation to body measures, sex, age, season and the use of drugs in patients with major affective disorders and healthy subjects. Psychoneuroendocrinology. 1984;9:261-77.

112. Novakova M, Prasko J, Latalova K, Sladek M, Sumova A. The circadian system of patients with bipolar disorder differs in episodes of mania and depression. Bipolar Disord. 2015;17:303-14.

113. Nurnberger JI Jr., Adkins S, Lahiri DK, Mayeda A, Hu K, Lewy A, et al. Melatonin suppression by light in euthymic bipolar and unipolar patients. Arch Gen Psychiatry. 2000;57:572-9.

114. Cuthbert BN. Research Domain Criteria: toward future psychiatric nosologies. Dialogues Clin Neurosci. 2015;17:89-97.

\section{ACKNOWLEDGEMENTS}

This study was supported by a Fonds de recherche du Québec - Santé (FRSQ) \#252872 and \#265693, Quebec, Canada, Junior 1 Operating and Salary grant (OL). The authors declare no conflict of interest.

\section{AUTHOR CONTRIBUTIONS}

Eunsoo Moon has participated in the conception or design of the work, data acquisition, analysis, interpretation of the data, drafting and revising the manuscript.
Timo Partonen and Serge Beaulieu have participated in the conception or design of the work, interpretation of the data, revising the manuscript. Outi Linnaranta has participated in the conception or design of the work, data acquisition, analysis, interpretation of the data, drafting and revising the manuscript.

\section{FUNDING}

Open Access funding provided by National Institute for Health and Welfare (THL).

\section{COMPETING INTERESTS}

The authors declare no competing interests.

\section{ADDITIONAL INFORMATION}

Supplementary information The online version contains supplementary material available at https://doi.org/10.1038/s41386-022-01278-5.

Correspondence and requests for materials should be addressed to Outi Linnaranta.

Reprints and permission information is available at http://www.nature.com/ reprints

Publisher's note Springer Nature remains neutral with regard to jurisdictional claims in published maps and institutional affiliations.

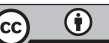

Open Access This article is licensed under a Creative Commons Attribution 4.0 International License, which permits use, sharing, adaptation, distribution and reproduction in any medium or format, as long as you give appropriate credit to the original author(s) and the source, provide a link to the Creative Commons license, and indicate if changes were made. The images or other third party material in this article are included in the article's Creative Commons license, unless indicated otherwise in a credit line to the material. If material is not included in the article's Creative Commons license and your intended use is not permitted by statutory regulation or exceeds the permitted use, you will need to obtain permission directly from the copyright holder. To view a copy of this license, visit http://creativecommons. org/licenses/by/4.0/.

(c) The Author(s) 2022 